\title{
Pharmacologic Inhibition of ROCK2 Suppresses Amyloid- $\beta$ Production in an Alzheimer's Disease Mouse Model
}

\author{
Jeremy H. Herskowitz, ${ }^{1,2}$ Yangbo Feng, ${ }^{5}$ Alexa L. Mattheyses, ${ }^{3}$ Chadwick M. Hales, ${ }^{1,2}$ Lenora A. Higginbotham,, 2 \\ Duc M. Duong, ${ }^{4}$ Thomas J. Montine, ${ }^{6}$ Juan C. Troncoso, ${ }^{7}$ Madhav Thambisetty, ${ }^{8}$ Nicholas T. Seyfried, ${ }^{1,4}$ Allan I. Levey, ${ }^{1,2}$ \\ and James J. Lah ${ }^{1,2}$ \\ ${ }^{1}$ Center for Neurodegenerative Disease, and Departments of ${ }^{2}$ Neurology, ${ }^{3}$ Cell Biology, and ${ }^{4}$ Biochemistry, Emory University School of Medicine, Atlanta, Georgia \\ 30322, ${ }^{5}$ Medicinal Chemistry, Translational Research Institute, The Scripps Research Institute, Jupiter, Florida 33458, ${ }^{6}$ Department of Pathology, University of \\ Washington, Seattle, Washington 98104, ${ }^{7}$ Departments of Pathology and Neurology, Johns Hopkins School of Medicine, Baltimore, Maryland 21205, and ${ }^{8}$ Unit of \\ Clinical and Translational Neuroscience and Laboratory of Behavioral Neuroscience, National Institute on Aging, Baltimore, Maryland 21224
}

\begin{abstract}
Alzheimer's disease $(\mathrm{AD})$ is the leading cause of dementia and has no cure. Genetic, cell biological, and biochemical studies suggest that reducing amyloid- $\beta(\mathrm{A} \beta)$ production may serve as a rational therapeutic avenue to delay or prevent $\mathrm{AD}$ progression. Inhibition of RhoA, a Rho GTPase family member, is proposed to curb $A \beta$ production. However, a barrier to this hypothesis has been the limited understanding of how the principal downstream effectors of RhoA, Rho-associated, coiled-coil containing protein kinase (ROCK) 1 and ROCK2, modulate $\mathrm{A} \beta$ generation. Here, we report that ROCK1 knockdown increased endogenous human A $\beta$ production, whereas ROCK 2 knockdown decreased A $\beta$ levels. Inhibition of ROCK2 kinase activity, using an isoform-selective small molecule (SR3677), suppressed $\beta$-site APP cleaving enzyme 1 (BACE1) enzymatic action and diminished production of $\mathrm{A} \beta$ in $\mathrm{AD}$ mouse brain. Immunofluorescence and confocal microscopy analyses revealed that SR3677 alters BACE1 endocytic distribution and promotes amyloid precursor protein (APP) traffic to lysosomes. Moreover, SR3677 blocked ROCK2 phosphorylation of APP at threonine 654 (T654); in neurons, T654 was critical for $\mathrm{APP}$ processing to $\mathrm{A} \beta$. These observations suggest that ROCK2 inhibition reduces $\mathrm{A} \beta$ levels through independent mechanisms. Finally, ROCK 2 protein levels were increased in asymptomatic $\mathrm{AD}$, mild cognitive impairment, and $\mathrm{AD}$ brains, demonstrating that R0CK2 levels change in the earliest stages of $\mathrm{AD}$ and remain elevated throughout disease progression. Collectively, these findings highlight R0CK2 as a mechanism-based therapeutic target to combat $\mathrm{A} \beta$ production in $\mathrm{AD}$.
\end{abstract}

\section{Introduction}

Alzheimer's disease $(\mathrm{AD})$ is the leading cause of dementia with no effective treatment. There is abundant evidence that the amyloid precursor protein (APP) and its derivative, amyloid- $\beta(\mathrm{A} \beta)$ peptide, play central roles in $\mathrm{AD}$. $\mathrm{A} \beta$ accumulates in senile plaques, a pathological hallmark of AD (Masters et al., 1985), and APP gene mutations cause chromosome 21-linked familial AD (FAD; Goate et al., 1991; Murrell et al., 1991). FAD cases display a neuropathological

\footnotetext{
Received June 13, 2013; revised 0ct. 3, 2013; accepted 0ct. 22, 2013.

Author contributions: J.H.H., N.T.S., A.I.L., and J.J.L. designed research; J.H.H., A.L.M., C.M.H., L.A.H., and D.M.D. performed research; J.H.H.,Y.F., T.J.M., J.C.T., and M.T. contributed unpublished reagents/analytic tools; J.H.H.,Y.F., A.L.M., C.M.H., D.M.D., N.T.S., A.I.L., and J.J.L. analyzed data; J.H.H., A.I.L., and J.J.L. wrote the paper.

This work was supported by the National Institutes of Health through National Institute on Aging (NIA) Grant 5K99AG043552- 02 to J.H.H., National Institute of Neurological Disorders and Stroke (NINDS) Grant P30NS055077, and NIA Grants AG025688, P01AG1449, and AG05136. This work was supported in part by the NIA Intramural Research Program of the National Institutes of Health. J.C.T. was supported by grants from the Johns Hopkins University Alzheimer's Disease Research Center (NIAAG05146) and the Alzheimer's Association (IIRG-09-134090). N.T.S. is supported by Alzheimer's Association Grant NIRG-12-242297. We thank the donors of ADR, a program of the BrightFocus Foundation, for support of this research. This research project was supported in part by the Emory University Integrated Cellular Imaging Microscopy Core of the Emory Neuroscience NINDS Core Facilities grant. We thank Dr. Ranjita Betarbet and Craig Heilman for technical assistance.

The authors declare no competing financial interests.

Correspondence should be addressed to Dr. James J. Lah, Center for Neurodegenerative Disease, 615 Michael Street, Suite 505, Atlanta, GA 30322. E-mail: jlah@emory.edu.

DOI:10.1523/JNEUROSCI.2508-13.2013

Copyright $\odot 2013$ the authors $\quad 0270-6474 / 13 / 3319086-13 \$ 15.00 / 0$
}

phenotype similar to sporadic $\mathrm{AD}$, and the observation that all known FAD mutations enhance or modify the production of $\mathrm{A} \beta$ provided the mechanistic foundation for the amyloid cascade hypothesis (Hardy, 1997). While A $\beta$ alone cannot account for all features of $\mathrm{AD}$, reducing $\mathrm{A} \beta$ production or accumulation is central to therapeutic strategies aimed at disease modification.

$\mathrm{A} \beta$ is generated by sequential proteolytic cleavage of APP by $\beta$-site APP cleaving enzyme (BACE) 1 and the subsequent action of $\gamma$-secretase. Characterization of the APP Swedish mutation at the BACE1 cleavage site highlighted the potency of modulating this pathway in regulating A $\beta$ generation (Mullan et al., 1992; Citron et al., 1995). Moreover, genetic studies in a population of Icelanders indicated that an APP amino acid substitution that abrogates cleavage by BACE1 protects against AD (Jonsson et al., 2012). Generating viable BACE1 small-molecule inhibitors has met substantial roadblocks due to the size of the BACE1 enzymatic site and the lack of pharmacokinetic efficacy in vivo (Stachel, 2009). However, alternative small-molecule approaches to reduce $A \beta$ production have been explored, including $\gamma$-secretase inhibitors/modulators and nonsteroidal anti-inflammatory drugs (NSAIDs; De Strooper et al., 2010).

One way that NSAIDs are proposed to reduce $A \beta$ is through the inhibition of Rho-GTPases and their principal downstream effectors, Rho-associated, coiled-coil containing protein kinase (ROCK) 1 and ROCK2 (Zhou et al., 2003). ROCK1 and ROCK2 are ubiquitous serine/threonine kinases that share $65 \%$ similarity 
in their amino acid sequences and 92\% identity in their kinase domains (Nakagawa et al., 1996). Exposure to Y-27632, a drug that inhibits ROCK1 and ROCK2 with similar potency (Uehata et al., 1997), reduced brain levels of $\mathrm{A} \beta 42$ in an $\mathrm{AD}$ mouse model but had no appreciable effect on total soluble $\mathrm{A} \beta$ (Zhou et al., 2003). These studies suggested that ROCK inhibition might serve as a rational avenue to curb $\mathrm{A} \beta$ production. However, this promising hypothesis has languished somewhat in recent years due to the limited understanding of how the Rho/ROCK pathway modulates $\mathrm{A} \beta$ generation and which ROCK isoform is responsible for these effects. In this report, the effects of ROCK1 or ROCK2 knockdown on $A \beta$ generation are defined. We show that, following treatment with a small-molecule inhibitor of ROCK2, APP processing to $A \beta$ was dramatically reduced in cellular and animal models of $\mathrm{AD}$, and mechanisms contributing to the observed effects were identified.

\section{Materials and Methods}

Cell culture, transduction, and transfection. SH-SY5Y human neuroblastoma and HEK293 cells were maintained in Eagle's minimal essential media or DMEM (Lonza), respectively, with $10 \%$ fetal bovine serum, and $1 \%$ penicillin/streptomycin. Primary cortical neuronal cells were prepared from embryonic day 17 mouse embryos and maintained in neurobasal medium supplemented with $0.8 \mathrm{~mm}$ L-glutamine and B27. Cortical tissue was dissected from mouse embryos and trypsin digested. Cells were plated at a density of 100,000 cells $/ \mathrm{cm}^{2}$ in 12 -well dishes that were coated with $100 \mu \mathrm{g} / \mathrm{ml}$ poly-lysine. On day 3 postplating, neurons were transduced with indicated lentivirus with a multiplicity of infection of 1 . For $\mathrm{A} \beta$ studies, at $72 \mathrm{~h}$ post-transduction cells were treated with drugs in conditioned media for $16 \mathrm{~h}$. For RNAi knockdown of ROCK1 or ROCK2, cells were harvested $96 \mathrm{~h}$ post-transduction. For transductions or transfections, equivalent amounts of cells were plated, and transfections were performed using Lipofectamine 2000 (Invitrogen) according to the manufacturer's instructions.

DNA constructs and lentivirus. The plasmid template for lentivirus generation is pLENTI, and lentivirus was generated by the Emory University Viral Vector Core. To express human wild-type (WT) $\mathrm{APP}_{695}, \mathrm{cDNA}$ encoding $\mathrm{APP}_{695}$ was cloned into pLENTI using BamH1 and EcoR1 sites. Lentivirus vectors for shRNA expression were constructed as previously described (Herskowitz et al., 2012). The following shRNA sequences were used: human ROCK1 shRNA 1, 5' -GCCAATGACTTACTTAGGA; human ROCK1 shRNA 2, 5' -CTACAAGTGTTGCTAGTTT; human ROCK2 shRNA 1, 5' ATCAGACAGCATCCTTTCT; human ROCK2 shRNA 2, 5' -GCAAATCT GTTAATACTCG; scramble, 5'-GGACTACTCTAGACGTATA; mouse ROCK2 shRNA, 5'-CAATGAAGCTTCTTAGTAA. To generate ROCK1 and ROCK2 mutants resistant to human shRNA 1 sequences, cDNA encoding human ROCK1 (a gift from Dr. Lei Wei, Indiana University School of Medicine, Indianapolis, IN) or ROCK2 (a gift from Dr. Anming Meng, Tsinghua University, Beijing, China) was used as a template, and QuikChange XL Site-directed Mutagenesis kit (Stratagene) was used (Lee et al., 2009; Zhang et al., 2009). For ROCK1, the sense primer was 5' -CTG AAG AAG AAA CAG TAC GCA TCC ATT CAT CAT GGT GTG GTG GAG, and the antisense primer was $5^{\prime}$-AGC TGT GTC CGA TTC TGT CCT AAG CAA ATC ATT GGC TTC TTC TAG CAG. For ROCK2, the sense primer was 5' -C GG TGG AAG AAA TCA GAC AAC ACC CTT TCT TTA AGA ATG ATC AGT G, and the antisense primer was 5'-CAC TGA TCA TTC TTA AAG AAA GGG TGT TGT CTG ATT TCT TCC ACC. To generate APP threonine 654A (T654A), cDNA encoding $\mathrm{APP}_{695}$ was used as a template, and the QuikChange XL Site-directed Mutagenesis kit was used. For T654A, the sense primer was $5^{\prime}$-CTG AAG AAG AAA CAG TAC GCA TCC ATT CAT CAT GGT GTG GTG GAG, and the antisense primer was 5' -CTC CAC CAC ACC ATG ATG AAT GGA TGC GTA CTG TTT CTT CTT CAG. Constructs expressing human wild-type BACE1 CDNA or BACE1 at serine 498 (S498A) were generated as previously described (Herskowitz et al., 2012). All constructs were verified by restriction digestion and sequencing.

Chemicals. For Rho inhibition, Rho Inhibitor I (RhoI; Cytoskeleton Inc) was used at $1 \mu \mathrm{g} / \mathrm{ml}$. To inhibit ROCKs, Y-27632 (Calbiochem) was dissolved in $\mathrm{H}_{2} \mathrm{O}$ at $50 \mu \mathrm{M}$, and Fasudil (HA-1077, Sigma-Aldrich) was dissolved in $\mathrm{H}_{2} \mathrm{O}$ and used at the indicated doses. To inhibit ROCK2, SR3677 was dissolved in $\mathrm{H}_{2} \mathrm{O}$ and used at indicated doses. To inhibit BACE1, $\beta$-secretase Inhibitor IV (BI IV; Calbiochem) was used at $10 \mu \mathrm{M}$. The vehicle control (labeled "mock") was $\mathrm{H}_{2} \mathrm{O}$ for all experiments.

$A \beta$ measurements. For cells, media were conditioned for $16 \mathrm{~h}$, and then collected with cells for biochemical analyses. For brain tissue, soluble lysate was prepared as described below. $\mathrm{A} \beta$ was detected using a sandwich ELISA for human $\mathrm{A} \beta 40$ or $\mathrm{A} \beta 42$ (Millipore) following the manufacturer's instructions. Plates were read at $450 \mathrm{~nm}$ on a Spectra Max Plus plate reader (Molecular Devices).

Cell lysate and mouse tissue preparation and immunoblotting. Cells were lysed in PBS plus protease inhibitor mixture (PIC; Roche Diagnostics); Halt phosphatase inhibitor mixture (Pierce); and lysis buffer containing $0.5 \%$ Nonidet P- $40,0.5 \%$ deoxycholate, $150 \mathrm{~mm}$ sodium chloride, and 50 mм Tris, pH 7.4 (PBS+PIC+Halt+lysis buffer). Tissue was homogenized (dounce homogenizer) in the PIC + Halt + lysis buffer described above. Homogenized tissue or cell lysate was subjected to a 13,000 rpm spin to remove nuclei and debris. Cleared lysate was used for the indicated biochemical assay. Immunoblotting was performed using standard procedures as described previously (Herskowitz et al., 2011). To load equivalent amounts of lysate per sample, protein concentration was determined by bicinchoninic acid method (Pierce). Actin was used as loading control. Images were captured using an Odyssey Image Station (LI-COR), and band intensities were quantified using Scion Image.

Antibodies. The following antibodies were used: ROCK1, ROCK2, and actin (Abcam); APP and $\alpha$-secretase cleaved APP $(\operatorname{sAPP} \alpha$; 6E10, Covance); sAPP $\beta$ (192wt or 192swe for 5XFAD, Elan Pharmaceuticals); APP for immunocytochemistry (C8; a gift from Dr. Dennis Selkoe, Harvard Medical School, Boston, MA); BACE1 (Abcam); pMLC-Ser19 (Cell Signaling Technology); EEA1 (BD Biosciences); CD63 (BD Biosciences); LAMP1 (Developmental Studies Hybridoma Bank, University of Iowa, Iowa City, IA); ionized calcium-binding adapter molecule 1 (Iba1; Wako); and glial fibrillary acidic protein (GFAP; BIOCARE Medical).

Cell viability assay. Primary neuronal culture cell viability was measured using the CellTiter 96 Nonradioactive Cell Proliferation Assay (Promega) following the manufacturer's instructions. Absorbance was measured at $570 \mathrm{~nm}$ with a reference wavelength at $650 \mathrm{~nm}$. Cell death values were calculated as the percentage of control absorbance.

Stereotaxic injection. Twelve-week-old 5XFAD transgenic mice of either sex were anesthetized with $80 \mathrm{mg} / \mathrm{kg}$ ketamine and $8 \mathrm{mg} / \mathrm{kg}$ xylazene, and placed in a stereotaxic frame. Eyes were covered in ophthalmic ointment. Scalp was sterilized before skull exposure and incision. Unilateral injections of $\mathrm{H}_{2} \mathrm{O}$ or SR3677 were given at a rate of $1 \mu \mathrm{l} / 3 \mathrm{~min}$ into the left and right hemispheres (anteroposterior, $-2.1 \mathrm{~mm}$ from bregma; mediolateral, $\pm 1.8 \mathrm{~mm}$ from midline; and dorsoventral, $-1.8 \mathrm{~mm}$ from the surface of dura). Following stereotaxic injection, scalp was stapled and sterilized. Twenty-four hours later, mice were anesthetized with isoflurane and decapitated. Hemispheres were rapidly harvested and stored at $-80^{\circ} \mathrm{C}$ until further processing for biochemical analyses.

BACE1 activity assay. The BACE1 Activity Detection Kit (Sigma-Aldrich) was used to measure BACE1 activity from cells, brain, and in vitro assays following the manufacturer's instructions. For cells and brain homogenate, 100 or $500 \mu \mathrm{g}$ was used, respectively, per sample. All fluorescent readings were taken using a Synergy 2 Alpha microplate reader (BioTek).

In vitro kinase assay and liquid chromatography coupled with tandem mass spectrometry. Synthetic BACE1 peptides (ab41766, Abcam) or APP peptides (AnaSpec) were incubated with recombinant ROCK2 protein (Abcam), 200 $\mu \mathrm{M}$ ATP, and 1X NEB PK buffer for $3 \mathrm{~h}$ at $30^{\circ} \mathrm{C}$. Samples were trypsin digested, and the resulting peptides were analyzed independently by reversephase liquid chromatography coupled with tandem mass spectrometry (LCMS/MS), as previously described (Herskowitz et al., 2010).

Immunocytochemistry and confocal microscopy. Immunocytochemistry and confocal microscopy experiments were performed as previously described (Herskowitz et al., 2012). Briefly, HEK293 cells were plated onto Matrigel extracellular matrix (BD)-coated coverslips in 12-well culture dishes $24 \mathrm{~h}$ after transfection. Cells were exposed to SR3677 for $6 \mathrm{~h}$, and subsequently fixed for $20 \mathrm{~min}$ in $2 \%$ paraformaldehyde and rinsed several times with PBS containing 0.5\% normal horse serum, $0.5 \%$ normal goat 
serum, and $0.05 \%$ saponin. The cells were blocked and permeabilized for 30 min with PBS containing 5\% normal horse serum, 5\% normal goat serum, $1 \%$ bovine serum albumin, and $0.05 \%$ saponin (blocking buffer) plus $0.05 \%$ Triton X-100. Cells were rinsed and incubated in primary antibody diluted in blocking buffer overnight at $4^{\circ} \mathrm{C}$. The next day, cells were rinsed and incubated for $1 \mathrm{~h}$ with both fluorophore-conjugated anti-rabbit and mouse secondary antibodies (Jackson ImmunoResearch) in blocking buffer. Cell nuclei were stained with Hoechst 333258 (Invitrogen) and mounted onto slides using Vectashield (Vector Laboratories). Images were captured using an Olympus IX81 FV1000 inverted confocal microscope. Colocalization analysis was conducted with ImageJ using JACoP (Just Another Colocalization Plugin) version 2.0 according to published methods (Bolte and Cordelières, 2006). Briefly, rolling ball background subtraction was applied (radius $=20$ pixels) to all images, and a threshold was selected (consistent across treatment and staining). The thresholded Mander's coefficient was calculated to determine the fraction of red overlapping green (M2). Experiments were performed in triplicate, and the data are presented as the mean \pm $1 \mathrm{SD}$.

Human brain tissue preparation and immunohistochemistry. Postmortem human brain tissue samples were provided by the University of Washington Alzheimer's Disease Research Center (ADRC) and its Adult Changes in Thought Study, as well as the Johns Hopkins ADRC and the Baltimore Longitudinal Study of Aging (Table 1; Shock et al., 1984). The soluble (S2) fraction was prepared from each case as previously described (Donovan et al., 2012). A sample of $50 \mu \mathrm{g}$ was used for immunoblots. Immunohistochemical staining procedures were performed as previously described (Herskowitz et al., 2010). Briefly, fixed $50 \mu \mathrm{m}$ cryopreserved sections of postmortem human frontal cortex were incubated with primary antibodies for $48 \mathrm{~h}$ at $4^{\circ} \mathrm{C}$. Tissue samples were incubated for $1 \mathrm{~h}$ with both fluorophore-conjugated anti-rabbit and mouse secondary antibodies (Jackson ImmunoResearch), and 5 min incubation with bisbenzamidine (Hoechst) was used to label nuclei. For ROCK2, tyramide signal amplification (PerkinElmer) was used.

Statistical analysis. All experiments were performed on at least biological triplicate samples, and statistical analysis was performed using Student's $t$ test for independent samples. Unless otherwise noted, all data are expressed as the percentage of the mean \pm SEM with respect to the control. Error bars represent SEM. Prism software (GraphPad Software) was used for all graphs.

\section{Results}

\section{Opposing outcomes of ROCK1 or ROCK2 knockdown on} endogenous human $\mathrm{A} \beta$ levels

To test whether Rho or pan-ROCK inhibition alters production of endogenous human $\mathrm{A} \beta$, SH-SY5Y neuroblastoma cells were exposed to RhoI ( $1 \mu \mathrm{g} / \mathrm{ml})$, pan-ROCK inhibitor Y-27632 (50 $\mu \mathrm{M})$, or vehicle $\left(\mathrm{H}_{2} \mathrm{O}\right.$, labeled mock), and secreted endogenous $\mathrm{A} \beta 40$ was measured by ELISA. Treatment with RhoI or Y-27632 reduced A $\beta 40$ $12 \%$, which is consistent with previous findings (Fig. 1A; Zhou et al., 2003). To determine how selective depletion of ROCK1 or ROCK2 influences APP processing to A $\beta, \mathrm{SH}-\mathrm{SY} 5 \mathrm{Y}$ cells were transduced with lentivirus expressing ROCK1-targeted, ROCK2-targeted, or scramble shRNA. Ninety-six hours later, levels of endogenous fulllength cell-associated APP, secreted $\operatorname{sAPP} \alpha$, and $\mathrm{A} \beta 40$ levels were measured by immunoblot or ELISA ( $\operatorname{APP} \beta$ as well as $A \beta 42$ were below the limit of detection). Densitometry analysis indicated that APP and $\operatorname{sAPP} \alpha$ were marginally reduced following RNAi depletion of ROCK2 (Fig. $1 B$ ). Secreted A $\beta 40$ levels were increased $65 \%$ from ROCK1 knock-down cells but decreased 50\% from ROCK2-depleted cells compared with scramble or mock controls (Fig. 1C). These results were confirmed following knockdown of ROCK1 or ROCK2 using a second set of shRNA sequences in human cells (Fig. 1D). To rescue effects on $\mathrm{A} \beta 40$ levels due to shRNA-mediated knockdown of ROCK1 or ROCK2, site-directed mutagenesis was used to generate ROCK1 and ROCK2 shRNA-resistant mutants (R1 rescue and
Table 1. Postmortem human brain tissue samples

\begin{tabular}{|c|c|c|c|c|c|c|}
\hline Case & CASI & CERAD & Braak stage & Age (years) & Gender & $\overline{\mathrm{PMI}}$ \\
\hline \multicolumn{7}{|c|}{ Control (N=11) } \\
\hline 1 & 99 & 0 & 0 & 78 & M & \\
\hline 2 & 97 & 0 & 2 & 87 & $\mathrm{~F}$ & \\
\hline 3 & 95 & 0 & 2 & 79 & $\mathrm{~F}$ & \\
\hline 4 & 96 & 0 & 2 & 92 & $\mathrm{~F}$ & \\
\hline 5 & 88 & 0 & 1 & 98 & $\mathrm{~F}$ & \\
\hline 6 & 89 & 0 & 2 & 86 & M & \\
\hline 7 & & 0 & 2 & 92 & $\mathrm{~F}$ & \\
\hline 8 & & 0 & 2 & 87 & M & \\
\hline 9 & & 1 & 2 & 71 & $\mathrm{~F}$ & 16 \\
\hline 10 & & 0 & 4 & 86 & M & 7 \\
\hline 11 & & 0 & 3 & 95 & M & 17 \\
\hline \multicolumn{7}{|c|}{ Asymptomatic $\mathrm{AD}(N=5)$} \\
\hline 1 & 98 & 2 & 3 & 86 & M & \\
\hline 2 & 97 & 2 & 3 & 92 & $\mathrm{~F}$ & \\
\hline 3 & 97 & 2 & 3 & 79 & M & \\
\hline 4 & 91 & 2 & 3 & 75 & $\mathrm{~F}$ & \\
\hline 5 & 96 & 2 & 4 & 77 & $\mathrm{~F}$ & \\
\hline \multicolumn{7}{|c|}{$\mathrm{MCl}(N=9)$} \\
\hline 1 & & 0 & 2 & 68 & M & 10 \\
\hline 2 & & 2 & 3 & 87 & M & 20 \\
\hline 3 & & 1 & 3 & 90 & M & 14 \\
\hline 4 & & 1 & 4 & 89 & M & 16 \\
\hline 5 & & 1 & 2 & 90 & M & 14 \\
\hline 6 & & 1 & 3 & 88 & $\mathrm{~F}$ & 14 \\
\hline 7 & & 2 & 4 & 82 & M & 5.5 \\
\hline 8 & & 2 & 4 & 78 & M & 4 \\
\hline 9 & & 2 & 4 & 101 & $\mathrm{~F}$ & 25 \\
\hline \multicolumn{7}{|c|}{$\mathrm{AD}(N=16)$} \\
\hline 1 & 43 & 2 & 6 & 83 & M & \\
\hline 2 & 78 & 3 & 6 & 89 & $\mathrm{~F}$ & \\
\hline 3 & 69 & 3 & 6 & 80 & $\mathrm{~F}$ & \\
\hline 4 & 41 & 3 & 5 & 92 & $\mathrm{~F}$ & \\
\hline 5 & 70 & 3 & 6 & 78 & $\mathrm{~F}$ & \\
\hline 6 & 83 & 3 & 6 & 85 & $\mathrm{~F}$ & \\
\hline 7 & & 3 & 4 & 98 & $M$ & 20 \\
\hline 8 & & 3 & 4 & 92 & M & 7 \\
\hline 9 & & 3 & 6 & 86 & $M$ & 15 \\
\hline 10 & & 3 & 6 & 82 & $F$ & 6 \\
\hline 11 & & 3 & 6 & 72 & $F$ & 10 \\
\hline 12 & & 3 & 6 & 92 & $\mathrm{~F}$ & 19 \\
\hline 13 & & 3 & 6 & 82 & $M$ & 23 \\
\hline 14 & & 3 & 6 & 83 & $\mathrm{~F}$ & 11 \\
\hline 15 & & 3 & 6 & 94 & $\mathrm{~F}$ & 17.5 \\
\hline 16 & & 3 & 6 & 91 & $F$ & 18 \\
\hline
\end{tabular}

Eleven cognitively normal, age-matched, pathology-free controls were compared to 5 asymptomatic AD (aAD) cases, $9 \mathrm{MCl}$ cases, and 16 sporadic AD cases. Case numbers correspond to numbers indicating immunoblot samples in Figure $7 A-C$. Tissue samples were collected from prospectively studied participants in the Baltimore Longitudina Study of Aging at the Johns Hopkins' ADRC, as well as from the University of Washington ADRC and its Adult Changes in Thought study. The case diagnosis is based on Mini Mental State Examination, Cognitive Abilities Screening Instrument (CASI) score, Consortium to Establish a Registry for Alzheimer's disease (CERAD) score, and Braak staging. All cases are matched as closely as possible for age, sex, and postmortem interval (PMI). Cases were categorized into four diagnostic groups, which included (1) cognitively normal controls without AD pathology, (2) cognitively normal asymptomatic AD with moderate-to-severe pathology, (3) MCI with moderate-to-severe pathology, and (4) definite $A D$ with severe pathology. It is important to note that none of these cases had any coexisting pathologies, such as stroke or Lewy body disease. The Mini Mental State Examination is the most commonly used test for complaints of memory problems or when a diagnosis of dementia is being considered. Severe-to-moderate AD patients have Mini Mental State Examination scores of $10-20$ of a possible total of 30 . CASI was used by the Adult Changes in Thought study. A CASI >90 (equivalent to Mini Mental State Examination score of $\sim 27$ ) excludes the lower quartile of cognitive performance to ensure removal of individuals with prodromal dementia. Demographics were matched as closely as possible across groups and to Baltimore Longitudinal Study of Aging study. CERAD $(0 \rightarrow 3)$ and Braak $(0$ $\rightarrow 6$ ) scales are measures for the severity of plaque and tangle accumulation, respectively. If values are blank, then information was not available. F, Female; $M$, male.

R2 rescue, respectively). SH-SY5Y cells were transduced with lentivirus expressing ROCK1-targeted, ROCK2-targeted, or scramble shRNA, and $72 \mathrm{~h}$ later cells were transiently transfected with the indicated plasmids. Expression of R1 rescue or 

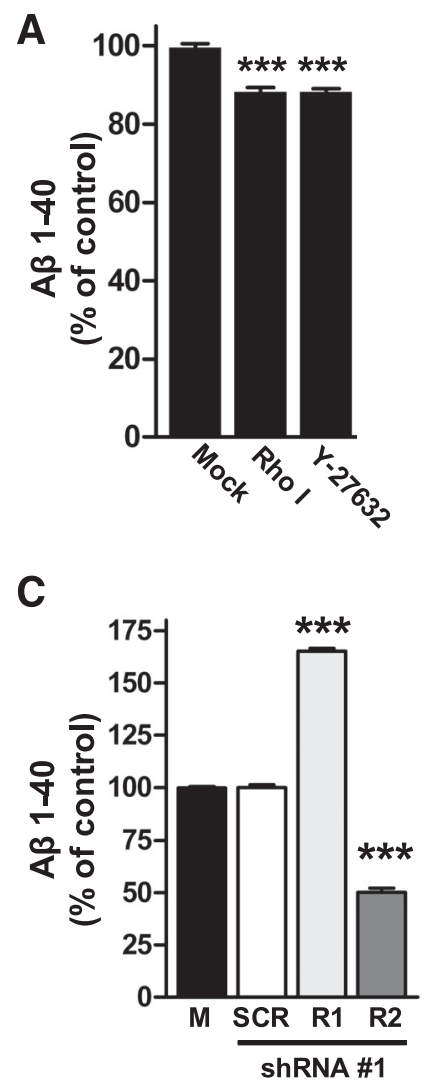

B

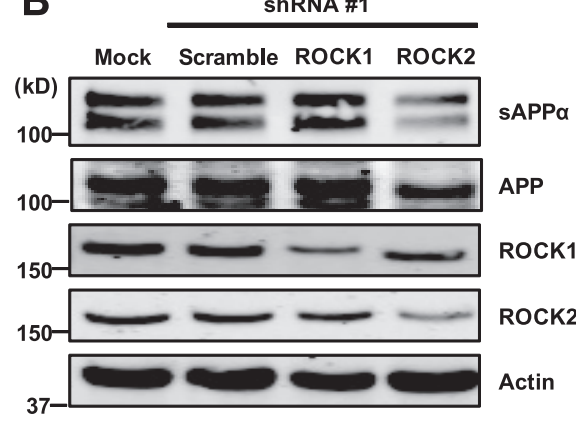

D

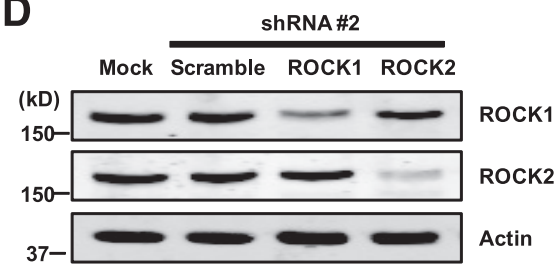

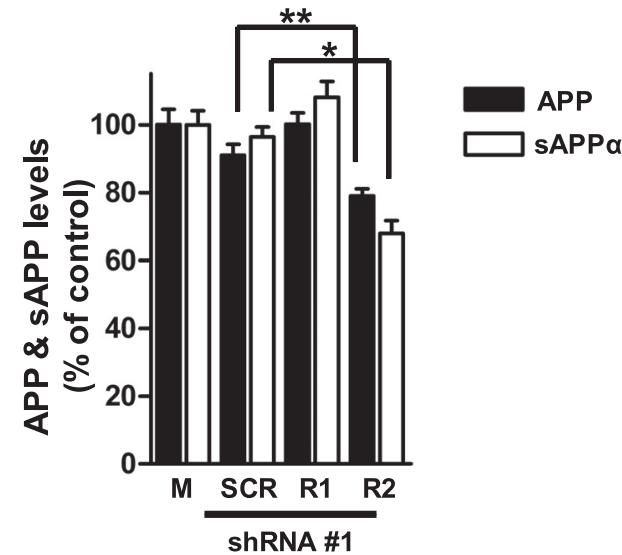

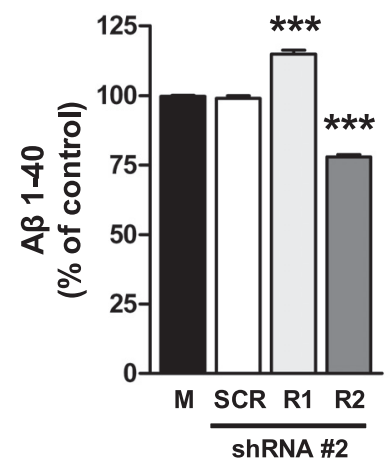

\section{E}
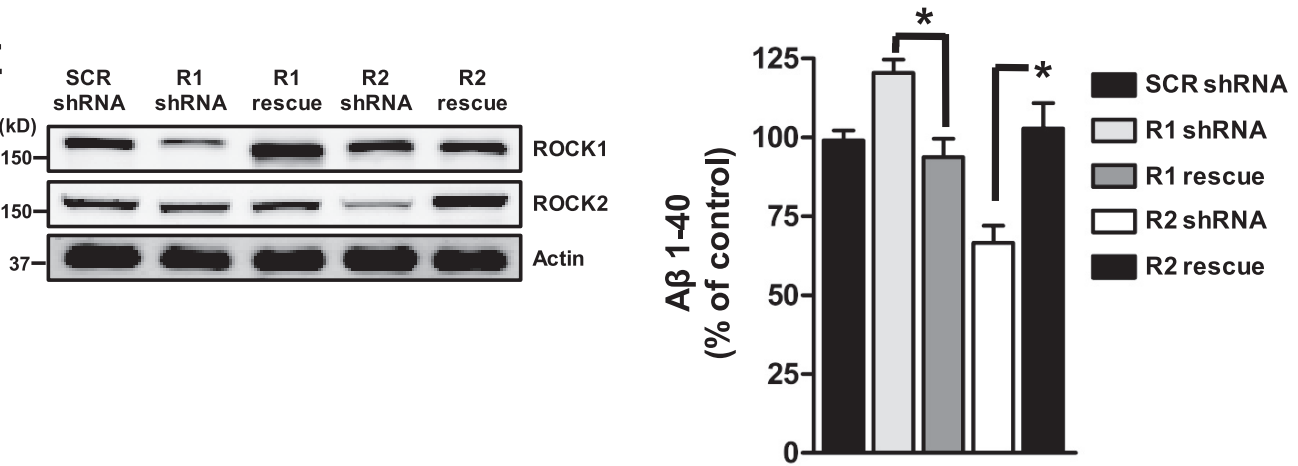

Figure 1. A $\beta$ levels were increased following ROCK1 knockdown, butwere decreased after ROCK2 knockdown.A, Human SH-SY5Y neuroblastoma cells were exposed to Rhol, Y-27632, orvehicle (Mock), and secreted endogenous A $\beta 40$ was measured by ELISA. Rhol or Y-27632 reduced A $\beta 4012 \%$ compared with mock. ${ }^{* *} p<0.0001$. B, SH-SY5Y cells were transduced with lentivirus expressing ROCK1-, ROCK2-, or scramble-shRNA, and APP, SAPP $\alpha$, and A $\beta 40$ were measured (representative blot shown). ROCK2 knockdown reduced endogenous APP and sAPP $\alpha\left(20 \%\right.$ and $32 \%$, respectively). ${ }^{*} p=0.032$, ${ }^{* *} p=0.0037$. C, A 340 was increased $65 \%$ and decreased $50 \%$ from ROCK1 or ROCK2 knock-down cells, respectively. $* * * 00.0001$. D, Effects of ROCK1 or ROCK2 knockdown on human endogenous A $\beta$ levels using a second set of shRNA sequences. HEK293 cells were transfected with plasmids expressing an alternate ROCK1-, ROCK2-, or scramble shRNA sequence, and $96 \mathrm{~h}$ post-transfection, secreted endogenous A $\beta 40$ was measured by ELISA. Representative immunoblot confirms shRNA-mediated knockdown of ROCK1 or ROCK2. Consistent with the shRNA experiments in $B$ and $C$, ROCK1 knockdown increased A $\beta 40$ levels $16 \%$, whereas ROCK2 knockdown decreased A $\beta 40$ levels $22 \%$ compared with scramble and mock-transfected controls. ${ }^{* * *} p<0.0001$. E, ROCK1 and ROCK2 shRNA-resistant mutants rescue effects on endogenous A $\beta$ levels following RNAi depletion of ROCK1 or ROCK2. SH-SY5Y cells were transduced with lentivirus expressing ROCK1-, ROCK2-, or scramble-shRNA and subsequently were transfected with plasmids expressing ROCK1 shRNA-resistant mutant (R1 rescue), ROCK2 shRNA-resistant mutant ( $R 2$ rescue), or empty vector, respectively. Forty-eight hours post-transfection, secreted endogenous $A \beta 40$ was measured by ELISA. Representative immunoblot confirms shRNA-mediated knockdown of ROCK1 or ROCK2, and the expression of R1 and R2 rescue. A 340 levels were comparable among scramble, R1 rescue, and R2 rescue samples (SCR: 99\%; R1 shRNA: 120\%; R1 rescue: 94\%; R1 shRNA vs R1 rescue, ${ }^{*} p=0.02 ; \mathrm{R} 2$ shRNA: 67\%; R2 rescue: $103 \% ; \mathrm{R} 2$ shRNA vs $\mathrm{R} 2$ rescue, $\left.{ }^{*} p=0.0204\right)$. M, Mock; $5 C \mathrm{R}$, scramble. $N=3-6$ biological replicates per condition. All data are expressed as the percentage of the mean \pm SEM with respect to mock or scramble control.

$\mathrm{R} 2$ rescue reversed effects on $\mathrm{A} \beta 40$ production that were observed following RNAi depletion of ROCK1 or ROCK2, respectively (Fig. 1E). Notably, the opposing outcomes of ROCK1 or ROCK2 knockdown on A $\beta$ levels in SH-SY5Y cells suggest that the net result of inhibiting both kinases is a limited effect, which was observed following treatment with RhoI or Y-27632. These findings suggest that selective inhibition of ROCK2 activity may reduce amyloidogenic processing of APP.
SR3677 reduces sAPP $\beta$ and A $\beta$ in a dose-dependent manner To address whether pharmacologic inhibition of ROCK2 activity influences $A \beta$ production, primary murine cortical neurons were transduced with lentivirus expressing wild-type human $\mathrm{APP}_{695}$, and secreted $\mathrm{A} \beta 40$ and $\mathrm{A} \beta 42$ was measured by ELISA following exposure to RhoI, Y-27632, or SR3677, a highly selective ROCK2 small-molecule inhibitor (Feng et al., 2008). Consistent with the findings above, treatment with RhoI or Y-27632 had little to no 
effect on $A \beta$, whereas SR3677 dramatically reduced $A \beta 40$ and A $\beta 42$ levels $>75 \%$ (Fig. 2A). To determine whether SR3677 has a similar effect on endogenous A $\beta$ in human cells, SH-SY5Y neuroblastoma cells were also tested. SR3677 treatment diminished endogenous secreted $A \beta 40$ levels by $68 \%$ (Fig. $2 B$ ). To further characterize the effects of SR3677 on APP processing to A $\beta$, primary neurons expressing $\mathrm{APP}_{695}$ were exposed to increasing doses of SR3677, and levels of full-length cell-associated APP, $\operatorname{sAPP} \alpha, \operatorname{sAPP} \beta$, and $\mathrm{A} \beta 40$ were measured by immunoblot or ELISA. Densitometry analysis indicated that the reduction of APP and sAPP $\alpha$ levels was significant at doses $\geq 20 \mu \mathrm{M}$, whereas sAPP $\beta$ and A $\beta 40$ both showed a more striking and linear dosedependent decrease in levels (Fig. 2 C,E). Fasudil, the only clinically approved ROCK inhibitor, lacks selectivity to ROCK1 or ROCK2 but has been used successfully to treat stroke patients without incidence of severe side effects (Shibuya et al., 2005). In contrast to SR3677, Fasudil treatment reduced A $\beta 40$ levels only $17-22 \%$ at concentrations $\geq 20 \mu \mathrm{M}$ in primary neurons expressing $\mathrm{APP}_{695}$ (Fig. 2E). Cell viability of primary neuronal cultures was not affected by SR3677 treatment (Fig. 2F). Furthermore, phosphorylation of myosin light chain 2 serine 19, a ROCK2 substrate (Totsukawa et al., 2000), was reduced in neurons exposed to SR3677 or RNAi depleted of ROCK2, verifying that SR3677 inhibits ROCK2 kinase activity in neurons (Fig. 2G). These results indicate that ROCK2 inhibition strongly suppresses amyloidogenic processing of APP in a dose-dependent manner. Moreover, the observation that SR3677 mirrored the effects of RNAi depletion of ROCK2 on APP processing to A $\beta$ strongly supports the conclusion that SR3677-induced phenotypes are the consequence of selective ROCK2 inhibition.

\section{SR3677 reduces BACE1 activity and A $\beta$ in 5XFAD mouse brain}

Without comprehensive knowledge of pharmacokinetic and CNS penetration properties, we sought to examine how acute exposure to SR3677 impacts APP processing to A $\beta$ in the 5 XFAD AD mouse model (Oakley et al., 2006). Twelve-week-old 5XFAD mice were treated with $2 \mathrm{mg} / \mathrm{kg}$ SR3677 or the same volume of vehicle $\left(\mathrm{H}_{2} \mathrm{O}\right.$, labeled mock) by stereotaxic injection into the hippocampus. Twenty-four hours later, the primary injection site (molecular layer of dentate gyrus) and the overlying parietal cortex intimately surrounding the needle track were extracted for biochemical assays. Each hemisphere was harvested separately, and brain homogenates were prepared for immunoblot to examine levels of APP and sAPP $\beta$. Densitometry analysis revealed that APP and sAPP $\beta$ were reduced to $68 \%$ and $23 \%$ of controls, respectively, in mice treated with SR3677 (Fig. 3A). Additionally, soluble $A \beta$ levels were measured by ELISA, and, consistent with our findings above, SR3677-treated mice displayed substantially less $\mathrm{A} \beta 40$ and $\mathrm{A} \beta 42$ compared with mock controls (Fig. $3 B$ ).

Based on the considerable reduction of $\operatorname{SAPP} \beta$ following exposure to SR3677, we hypothesized that ROCK2 inhibition suppresses APP processing by BACE1. To test this possibility, BACE1 activity was assayed using a fluorescence resonance energy transfer to measure cleavage of exogenous substrate $\left(\mathrm{APP}_{770}\right.$ peptide 667-676) in brain homogenates from 5XFAD mice. Analyses of SR3677-treated brains revealed that BACE1 activity was reduced $31 \%$ compared with mock controls (Fig. $4 A$ ), and immunoblots indicated that BACE1 protein levels were not altered in the presence of SR3677 (Fig. 3A). To explore the possibility that SR3677 directly inhibits BACE1, recombinant BACE1 protein was incubated with SR3677, BI IV, or vehicle, and enzyme activity was measured. While BI IV nullified activity, no change was observed in SR3677-treated samples, indicating that SR3677 does not directly inhibit BACE1 (Fig. 4B). Finally, to address whether ROCK2 inhibition attenuates endogenous human BACE1 activity, SH-SY5Y cells were exposed to increasing doses of SR3677 for $16 \mathrm{~h}$, and homogenates were analyzed for BACE1 enzymatic action. Similar to results in vivo, BACE1 activity was significantly reduced at doses $\geq 10 \mu \mathrm{M}$, while BACE1 protein levels remained static (Fig. 4C). Together, these findings suggest that the observed reduction in APP processing to $A \beta$ following ROCK2 inhibition is due in part to the suppression of BACE1 enzymatic activity.

Intracellular compartmentalization of BACE1 influences its enzymatic activity, and phosphorylation of the cytoplasmic tail of BACE1 at S498 regulates BACE1 traffic (Cole and Vassar, 2007). To test whether BACE1 $\mathrm{S} 498$ is a ROCK2 substrate, in vitro kinase assays were performed whereby synthetic peptides comprising BACE1 amino acids 485-501 were incubated in the presence or absence of recombinant ROCK2 protein. Peptides were independently analyzed by LC-MS/MS, and MS/MS spectra were collected and searched against a concatenated target-decoy database. Our LC-MS/MS data indicated that ROCK2 can phosphorylate BACE1 S498, and inspection of extracted ion intensities revealed that the presence of SR3677 completely blocked ROCK2 phosphorylation of BACE1 (Fig. 4D,E). No BACE1 phosphopeptides were found in the absence of ROCK2 (control).

BACE1 enzymatic activity is increased in sporadic AD cases and immunoprecipitation studies suggest that BACE1 is phosphorylated at S498 in AD brain (Fukumoto et al., 2002; Yang et al., 2003; von Arnim et al., 2004). Therefore, we wondered whether BACE1 S498 phosphorylation influences BACE1 activity. To test this, SH-SY5Y cells were transfected with constructs expressing wild-type BACE1 or mutant BACE1 harboring an alanine substitution at S498 (BACE1S498A). Twenty-four hours later, cell extracts were analyzed for BACE1 enzymatic action. In cells expressing BACE1S498A, enzymatic activity was reduced $20 \%$ compared with BACE1, indicating that mutagenesis of S498 to alanine suppresses BACE1 activity (Fig. $4 F$ ). Based on these findings, we hypothesize that the observed reduction in BACE1 activity following exposure to SR3677 may be due to the suppression of BACE1 S498 phosphorylation by ROCK2.

\section{SR3677 alters endocytic distribution of BACE1 and promotes APP traffic to lysosomes}

Cell biological studies indicate that APP processing is determined by its intracellular traffic and exposure to secretase enzymes, and that $A \beta$ is produced in the endosomal compartment (Sisodia, 1992; Koo and Squazzo, 1994; Hartmann et al., 1997). Therefore, we sought to determine whether the reduction in $\operatorname{APP} \beta$ and $\mathrm{A} \beta$ levels following ROCK2 inhibition is driven by changes in BACE1 endocytic traffic. To test this, BACE1 was transiently expressed in HEK293 cells growing on coverslips. The next day cells were treated with $50 \mu \mathrm{M}$ SR3677 or vehicle $\left(\mathrm{H}_{2} \mathrm{O}\right.$, labeled mock) for 6 h. After fixation, cells were stained for BACE1 along with markers for early endosomes (EEA1), late endosomes (CD63), or lysosomes (LAMP1). BACE1 was localized by confocal microscopy, and analysis of the images revealed that in cells exposed to SR3677, BACE1 overlap with EEA1 was reduced but BACE1 colocalization with LAMP1 was markedly increased (Fig. $5 A, C$ ). BACE1 localization to CD63-positive compartments appeared elevated in SR3677-treated samples; however, quantitative analysis indicated that these changes were not significant compared with mock. These observations suggest that ROCK2 inhibition reduces BACE1 residence in early endosomes and promotes BACE1 traffic to lysosomes. Recent advances show that BACE1 cleavage of APP occurs in early endosomes; there- 

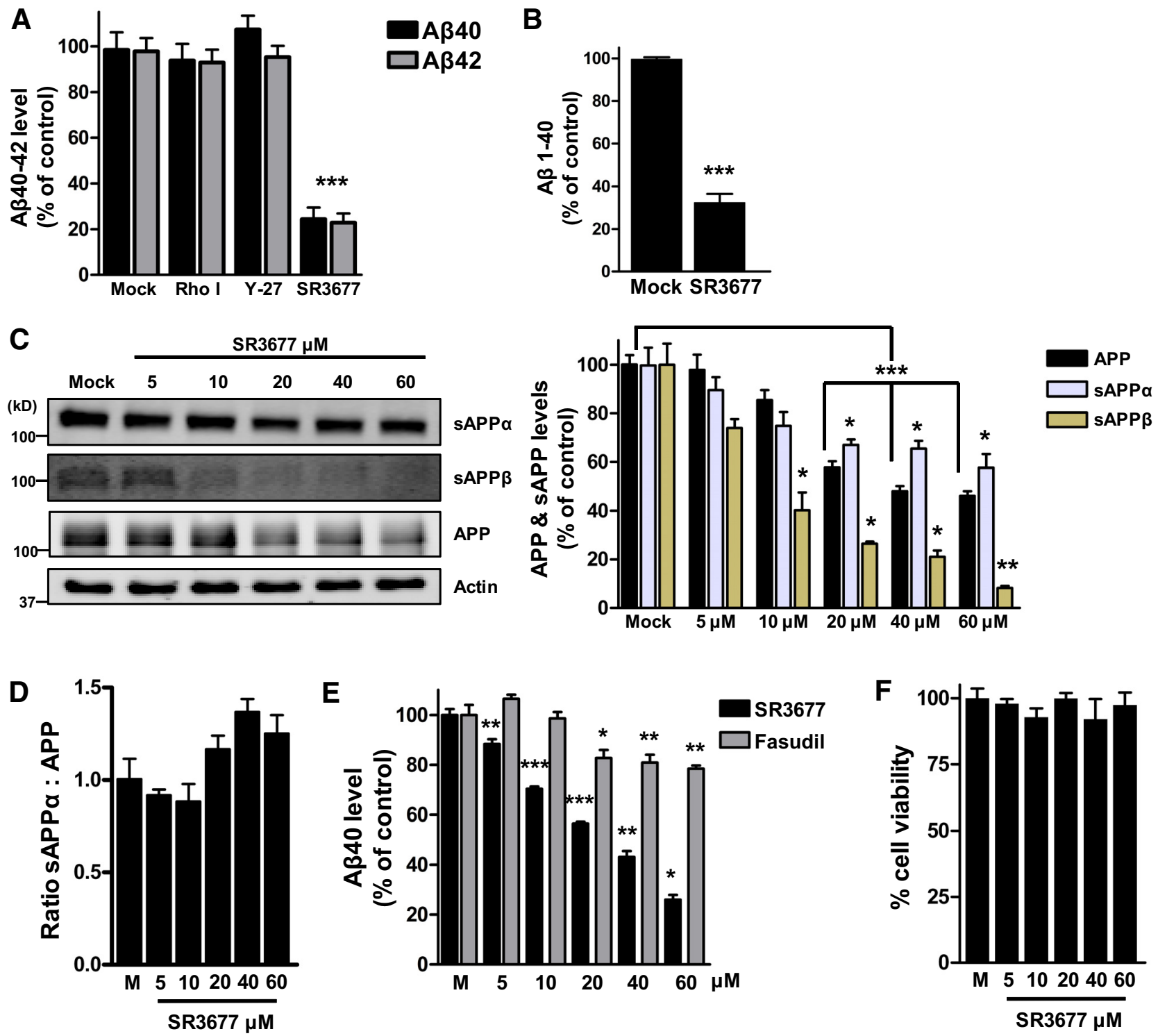

G
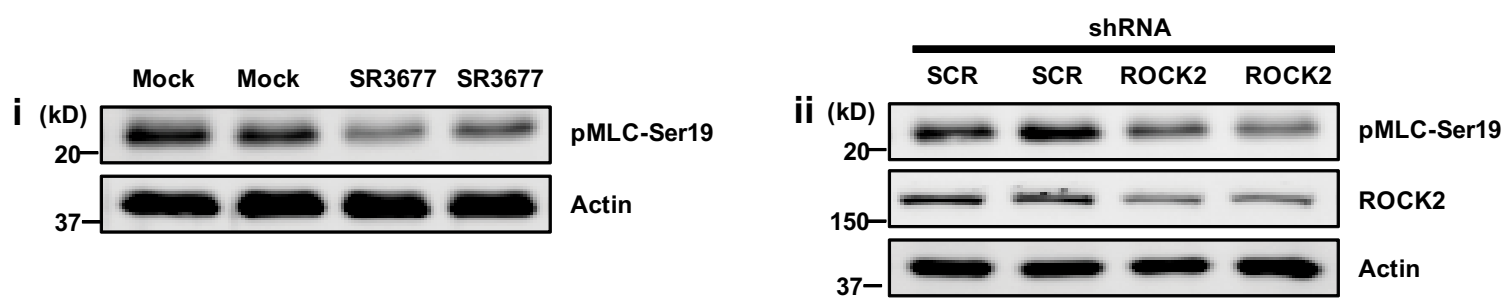

Figure 2. SR3677 reduces $S A P P \beta$ and $A \beta$ in a dose-dependent manner. $A$, Neurons were transduced with lentivirus expressing APP ${ }_{695}$ and exposed to $\mathrm{Rhol}_{1} \mathrm{Y}-27632(\mathrm{Y}-27,50 \mu \mathrm{M}), \mathrm{SR} 3677(50 \mu \mathrm{M})$, or $\mathrm{H}_{2} \mathrm{O}$ (Mock). SR3677 reduced A $\beta 40$ and A $\beta 42$ levels $76 \%$ and 78\%, respectively. ${ }^{* * *} p<0.0001$. B. Human SH-SY5Y neuroblastoma cells were exposed to SR3677 (50 $\mu$ M) or vehicle ( $\mathrm{H}_{2} 0$, labeled mock), and secreted endogenous $A \beta 40$ was measured by ELISA. Treatment with SR3677 reduced A $\beta 4068 \%$ compared with mock. ${ }^{* * *} p<0.0001$. C, Neurons expressing APP ${ }_{695}$ were exposed to SR3677 atindicated doses, and APP, SAPP $\alpha$, and sAPP $\beta$ were measured (representative blot shown). Densitometry analysis indicated changes in APP and sAPP $\alpha$ reached significance at concentrations $\geq 20 \mu \mathrm{m}$ (APP: $20 \mu \mathrm{m}, 58 \% ; 40 \mu \mathrm{m}$, $48 \% ; 60 \mu \mathrm{m}, 46 \% ; \mathrm{sAPP} \alpha: 20 \mu \mathrm{m}, 67 \% ; 40 \mu \mathrm{m}, 65 \% ; 60 \mu \mathrm{m}, 57 \% ; A P P$ :mockvs 20,40, or $60 \mu \mathrm{m},{ }^{* * *} p<0.001 ; \mathrm{sAPP} \alpha$ : mockvs 2040, or $\left.60 \mu \mathrm{m},{ }^{*} p \geq 0.01\right)$. Reduction of sAPP $\beta$ was dosedependent (sAPP $\beta$ : mock, 100\%; $5 \mu \mathrm{m}, 74 \% ; 10 \mu \mathrm{m}, 40 \% ; 20 \mu \mathrm{m}, 26 \% ; 40 \mu \mathrm{m}, 21 \% ; 60 \mu \mathrm{m}, 8 \%$; mock vs $10 \mu \mathrm{m},{ }^{*} p=0.0341 ;$ mock vs $20 \mu \mathrm{m},{ }^{*} p=0.0138$; mock vs $40 \mu \mathrm{m},{ }^{*} p=0.013 ;$ mock vs $\left.60 \mu \mathrm{m},{ }^{* *} p=0.0089\right)$. D, Densitometry analysis in C was used to calculate the ratio of sAPP $\alpha$ to APP. At higher concentrations of SR3677, the ratio of SAPP $\alpha$ to APP increases. E, Neurons expressing APP 695 were exposed to SR3677 or Fasudil at indicated doses, and $A \beta 40$ was measured by ELISA. SR3677 reduces $A \beta 40$ in a dose-dependentmanner (mock, $100 \% ; 5 \mu \mathrm{m}, 88 \% ; 10 \mu \mathrm{m}, 70 \% ; 20 \mu \mathrm{m}, 56 \% ; 40 \mu \mathrm{m}, 43 \% ; 60 \mu \mathrm{m}, 26 \%$; mockvs $5 \mu \mathrm{m}$, ${ }^{* *} p=0.0088 ; 5 \mathrm{vs} 10 \mu \mathrm{m},{ }^{* * *} p=0.0001 ; 10 \mathrm{vs} 20 \mu \mathrm{m},{ }^{* * *} p<0.0001 ; 20 \mathrm{vs} 40 \mu \mathrm{m},{ }^{* *} p=0.0016 ; 40 \mathrm{vs} 60 \mu \mathrm{m},{ }^{*} p=0.0301$ ). Fasudil reduces A $\beta 40$ marginally at doses $\geq 20 \mu \mathrm{m}$ (mock, $100 \% ; 5 \mu \mathrm{m}, 107 \%$; $10 \mu \mathrm{m}, 99 \% ; 20 \mu \mathrm{m}, 83 \% ; 40 \mu \mathrm{m}, 81 \% ; 60 \mu \mathrm{m}, 78 \%$; mock vs $20 \mu \mathrm{m},{ }^{*} p=0.0151$; mock vs $40 \mu \mathrm{m},{ }^{* *} p=0.0092$; mockvs $\left.60 \mu \mathrm{m},{ }^{* *} p=0.0022\right) . F$, Primary murine cortical neurons were exposed to vehicle $\left(\mathrm{H}_{2} \mathrm{O}\right.$, labeled mock) or the indicated doses of SR3677 for $16 \mathrm{~h}$. No gross changes in cell viability were observed under the indicated SR3677 concentrations. Gi, To verify that SR3677 can reduce ROCK2 kinase activity in neurons, primary murine cortical neurons were treated with SR3677 (20 $\mu \mathrm{M}$ ) or vehicle (mock) and harvested $16 \mathrm{~h}$ later to examine phosphorylation of myosin light chain 2 serine 19 (pMLC-Ser19), a ROCK2 substrate (Totsukawa etal., 2000), by immunoblot. Gii, In parallel, neurons were transduced with lentivirus driving expression of ROCK2-targeted or scramble shRNA, and 96h later neurons were harvested. Immunoblot analyses using a phospho-specific antibody againstSer19 revealed that exposureto SR3677 or RNAidepletion of ROCK2 similarly reduced levels of pMLC-Ser19, supporting thatSR3677 inhibits ROCK2 kinase activity inneurons. Actin used as a loading control. M, Mock; SCR, scramble. $N=3-6$ biological replicates per condition. All data are expressed as the percentage of the mean \pm SEM with respect to mock. 

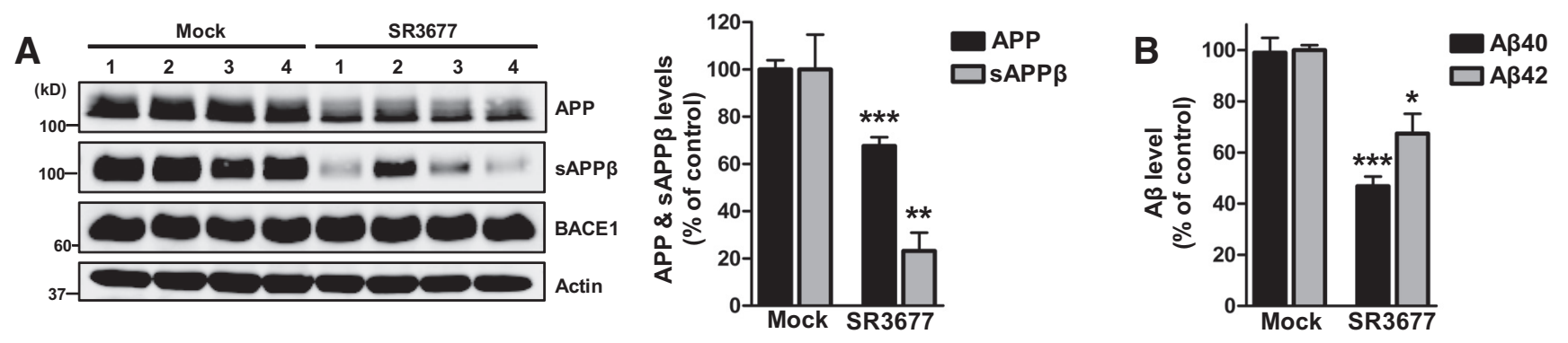

Figure 3. SR3677 reduces $A \beta$ in $5 X F A D$ mouse brain. SR3677 or $\mathrm{H}_{2} \mathrm{O}$ (mock) was stereotaxic injected into 5XFAD mouse brain. An injection was given on the left and right hemispheres. Each hemisphere was processed separately, and assay measurements for left and right hemispheres were averaged to yield one data point per brain (four mice per condition). Twenty-four hours after injection, brain homogenates were prepared for biochemical assays. $A$, Representative immunoblot shown. APP and SAPP $\beta$ were reduced $32 \%$ and $77 \%$, respectively, from brains injected with SR3677 compared with mock. ${ }^{* * *} p=0.001,{ }^{* *} p=0.0036 . B, A \beta 40$ and A $\beta 42$ levels were reduced $53 \%$ and $33 \%$, respectively, from SR3677 injected brains compared with mock. ${ }^{* * *} p<0.0001$, ${ }^{*} p=0.0105$. All data are expressed as the percentage of the mean \pm SEM with respect to mock.

fore, it is possible that the observed reduction in $\mathrm{SAPP} \beta$ levels after SR3677 treatment is due in part to redistribution of BACE1 to LAMP1-positive compartments (Sannerud et al., 2011). Notably, BACE1 protein levels are not altered in the presence of SR3677, suggesting that BACE1 may be rescued from lysosomal degradation (Figs. 3A, 4C; Koh et al., 2005).

In addition, endogenous APP traffic to lysosomes was evaluated in the presence or absence of SR3677 by immunofluorescence and confocal microscopy. Similar to BACE1, APP localized more strongly to LAMP1-positive compartments following SR3677 treatment (Fig. 5B,D). Notably, the APP antibody (C8) recognizes amino acids 676-695; therefore, our APP staining could reflect full-length APP as well as all C-terminal fragments (CTFs; Selkoe et al., 1988). Enhanced traffic of APP and/or APP CTFs to lysosomes may account for the reduction in APP protein level as well as $\mathrm{A} \beta$ levels that was observed following exposure to increasing concentrations of SR3677 (Fig. 2C).

\section{ROCK2 phosphorylates APP at T654, and T654 is critical for $\mathrm{A} \boldsymbol{\beta}$ generation in neurons}

Phosphorylation of the APP cytoplasmic tail is reported to play a role in APP processing to $A \beta$, and $\left[\gamma^{-32} \mathrm{P}\right]$ metabolic labeling studies revealed that the ROCK kinase domain can phosphorylate APP (Lee et al., 2003; Amano et al., 2010). Based on these observations, we hypothesized that ROCK2 phosphorylates the cytosolic domain of APP and that this action influences A $\beta$ generation. To identify putative sites of phosphorylation, in vitro kinase assays were performed whereby synthetic peptides comprising the full-length APP cytoplasmic tail were incubated in the presence or absence of recombinant ROCK2 protein. Peptides were independently analyzed by LC-MS/MS, and MS/MS spectra were collected and searched as described above. Our LC-MS/MS data identified a single APP phosphopeptide corresponding to phosphorylation at T654 (Fig. 6A). Moreover, inspection of extracted ion intensities revealed that incubation with SR3677 completely blocked ROCK2 phosphorylation of APP (Fig. 6B). No APP phosphopeptides were found in the absence of ROCK2 (control).

Since phosphorylation of APP at T654 is observed in brain (Oishi et al., 1997), we wondered whether T654 influences production of $A \beta$. Site-directed mutagenesis was used to substitute alanine for T654, generating the APP mutant T654A. To evaluate the effects of this mutation on $\mathrm{A} \beta$ production, primary cortical neurons were transduced with lentivirus expressing WT $\mathrm{APP}_{695}$ or T654A; and $72 \mathrm{~h}$ later, $\mathrm{APP}, \operatorname{sAPP} \alpha, \operatorname{sAPP} \beta$, and $\mathrm{A} \beta$ levels were evaluated by immunoblot or ELISA. Densitometry analysis re- vealed that $\mathrm{SAPP} \beta$ was depleted $42 \%$ by mutagenesis at T654 (Fig. $6 C)$. Secreted $A \beta 40$ and $A \beta 42$ levels were decreased $40 \%$ and $26 \%$, respectively, from those of T654A-expressing neurons (Fig. $6 D$ ). These findings indicate that $\mathrm{T} 654$, and possibly phosphorylation of T654 by ROCK2, is critical for APP processing by BACE1 and the generation of $A \beta$. Similar to T654A, a larger reduction in $\mathrm{A} \beta 40$ compared with $\mathrm{A} \beta 42$ was observed in $5 \mathrm{XFAD}$ brain following exposure to SR3677 (Fig. 3B). These distinct changes in $\mathrm{A} \beta$ isoforms may allude to a role for T654 phosphorylation in $\gamma$-secretase processing of APP C-terminal fragments.

The results above show that ROCK2 inhibition suppresses BACE1 activity and blocks ROCK2 phosphorylation of APP T654 in vitro; thus, we hypothesized that coupling SR3677 treatment with $\mathrm{T} 654 \mathrm{~A}$ would synergistically reduce $\mathrm{A} \beta$ levels. To test this, WT- or T654A-expressing neurons were exposed to a low dose of SR3677 $(20 \mu \mathrm{M})$, and $A \beta$ levels were measured by ELISA. Substantial decreases in $\mathrm{A} \beta 40$ and $\mathrm{A} \beta 42$ levels were observed from neurons expressing T654A after treatment with SR3677, indicating an additive effect of ROCK2 inhibition with mutagenesis of T654 (Fig. 6D). These observations suggest that inhibition of ROCK2 activity reduces $\mathrm{A} \beta$ production through at least two independent mechanisms.

\section{ROCK2 protein level is elevated in asymptomatic $A D, M C I$, and $\mathrm{AD}$ brains}

ROCK2 is a cytosolic kinase, and the accumulation of $A \beta$ may cause intracellular cytosolic proteins to lose solubility in $\mathrm{AD}$, effectively altering their function (Xu et al., 2013). To assess whether the ROCK2 protein level is changing in $\mathrm{AD}$ brain, frontal cortex tissue homogenates were prepared from $16 \mathrm{AD}$ and 11 age-matched pathology-free control cases (Table 1). Homogenates were subjected to SDS-PAGE and subsequent immunoblot (Fig. 7A-C). Densitometry analysis indicated that ROCK2 levels were elevated in $\mathrm{AD}$ brains compared with those of controls (Fig. $7 D$ ). To determine whether changes in ROCK2 occur early in disease progression, nine mild cognitive impairment (MCI) and five asymptomatic $\mathrm{AD}$ brains were analyzed. $\mathrm{MCI}$ is considered a prodromal phase of $\mathrm{AD}$, whereas asymptomatic $\mathrm{AD}$ is hypothesized to represent early disease stages between the first appearance of AD neuropathology and the onset of clinical symptoms (Driscoll and Troncoso, 2011; Sperling et al., 2011). ROCK2 protein levels were increased in MCI brains, and asymptomatic $\mathrm{AD}$ cases showed markedly elevated ROCK2 levels compared with controls. To determine whether changes in ROCK2 level are due to the accumulation of microglia or astrocytes in $\mathrm{AD}$ brain, immunohistochemical analysis was performed on four $\mathrm{AD}$ and four 
A

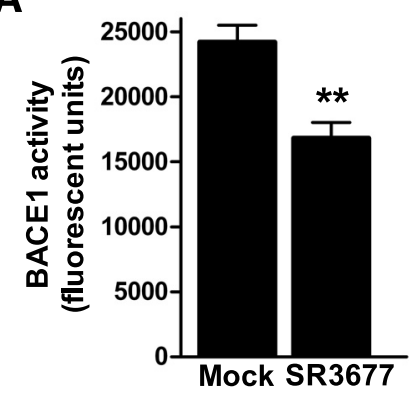

B

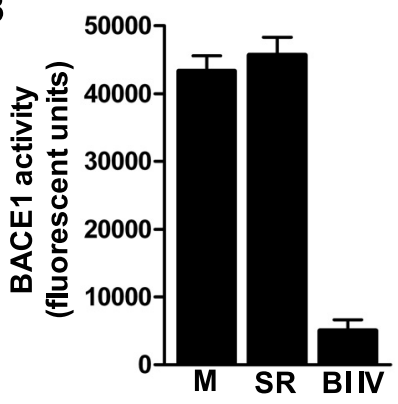

C

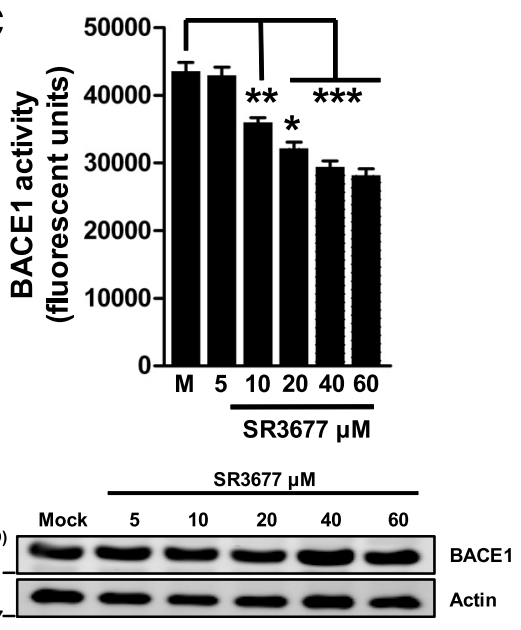

D

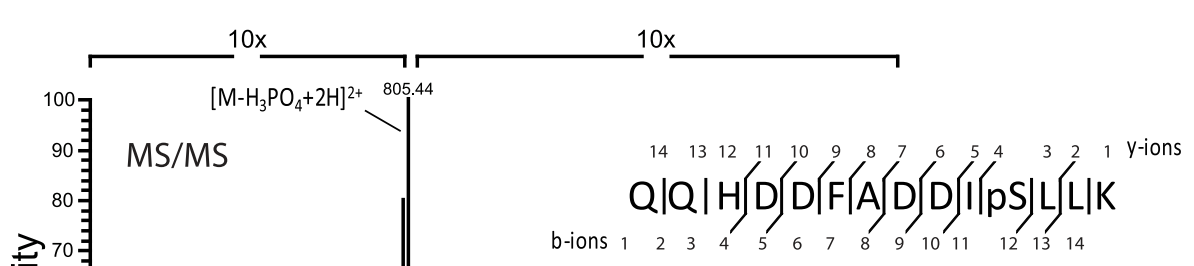

(BACE residues 488-501)

\section{E}

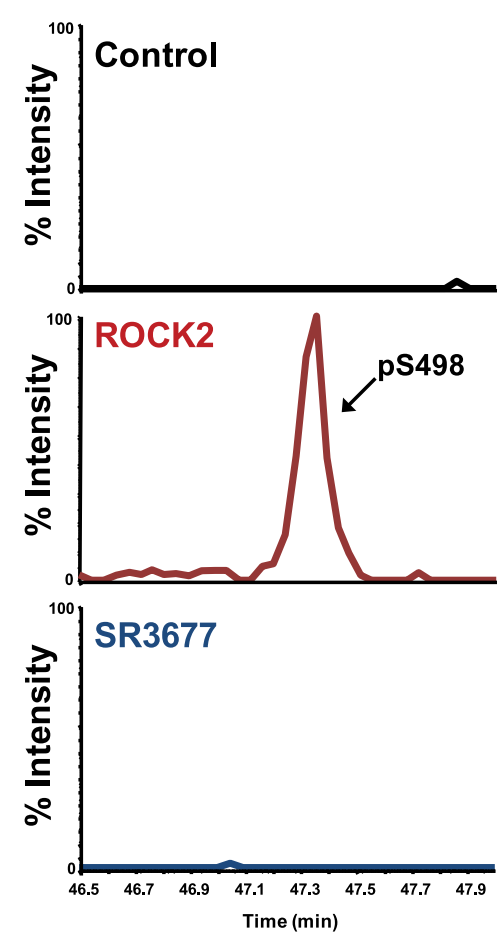

F

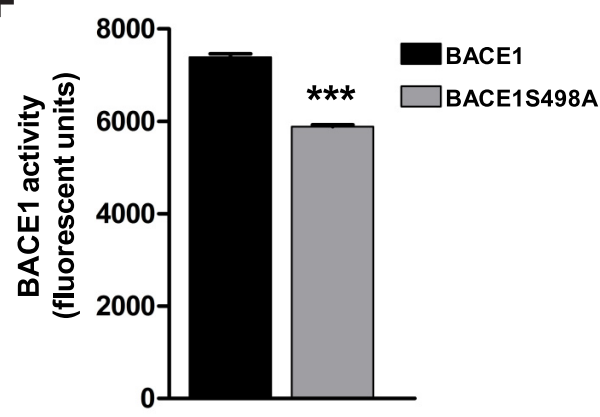

Figure 4. SR3677 suppresses BACE1 enzymatic activity in 5XFAD mouse brain. $A$, In drug-treated mice, BACE1 activity was reduced $\sim 31 \%$ as measured by fluorescent units. $B$, Recombinant BACE1 protein was incubated with $\mathrm{H}_{2} \mathrm{O}, \mathrm{SR3677}$, or BI IV, and enzyme activity was measured. C, SH-SY5Y cells were exposed to increasing doses of SR3677, and BACE1 activity was measured. At concentrations $\geq 10 \mu \mathrm{m}$, BACE1 activity was significantly reduced (mock vs $10 \mu \mathrm{m},{ }^{* *} p=0.0063$; mock vs 20,40 , or $60 \mu \mathrm{m},{ }^{* * *} p<0.002 ; 10$ vs $20 \mu \mathrm{m},{ }^{*} p=0.0281$ ). D, BACE1 peptides were incubated with recombinant ROCK2 protein \pm SR3677 and were examined by LC-MS/MS. Representative BACE1 S498 phosphopeptide spectrum displaying precursor neutral loss peak. $E$, Representative extracted ion chromatograms (measured as the percentage intensity using a defined precursor mass tolerance) for $\$ 498$ phosphopeptides. $x$-axis indicates time when the MS/MS spectrum was obtained. Peptide intensities were normalized to samples containing ROCK2 protein without SR3677. F, SH-SY5Y cells were transfected with BACE1 or BACE1S498A, and enzyme activity was measured $24 \mathrm{~h}$ later. Cells expressing BACE1S498A displayed a 20\% reduction in enzymatic action compared with BACE1. ${ }^{* * *} p<0.0001$. Representative immunoblot indicates BACE1 and BACE1S498A expression levels. M, Mock; SR, SR3677. N = 4-6 biological replicates per condition. All data are expressed as the percentage of the mean \pm SEM with respect to mock.

control cases. ROCK2 staining appeared neuronal and was elevated in cortical layers I-II of AD brains compared with controls. ROCK2 colocalization with cells positive for GFAP or Iba1, protein markers for mature astrocytes and microglia, respectively, was minimal (Fig. 7E). Collectively, these results demonstrate that ROCK2 levels are increased in the earliest stages of $\mathrm{AD}$ and remain elevated throughout disease progression. On the basis of these findings, coupled with our pharmacologic studies, we propose that ROCK2 is a mechanism-based therapeutic target to combat $\mathrm{A} \beta$ production for the treatment of $\mathrm{AD}$ progression.

\section{Discussion}

Effective therapies that combat the progression of $\mathrm{AD}$ do not currently exist. However, studies in animal models of AD provide strong evidence that reducing $\mathrm{A} \beta$ production may ease symptoms and slow disease progression. BACE1 cleavage of APP is the rate-limiting step in the generation of $A \beta$; therefore, constraining this step would decrease $A \beta$ production. While developing small molecules to inhibit BACE1 has met with substantial challenges, the findings herein provide a novel avenue to suppress BACE1 


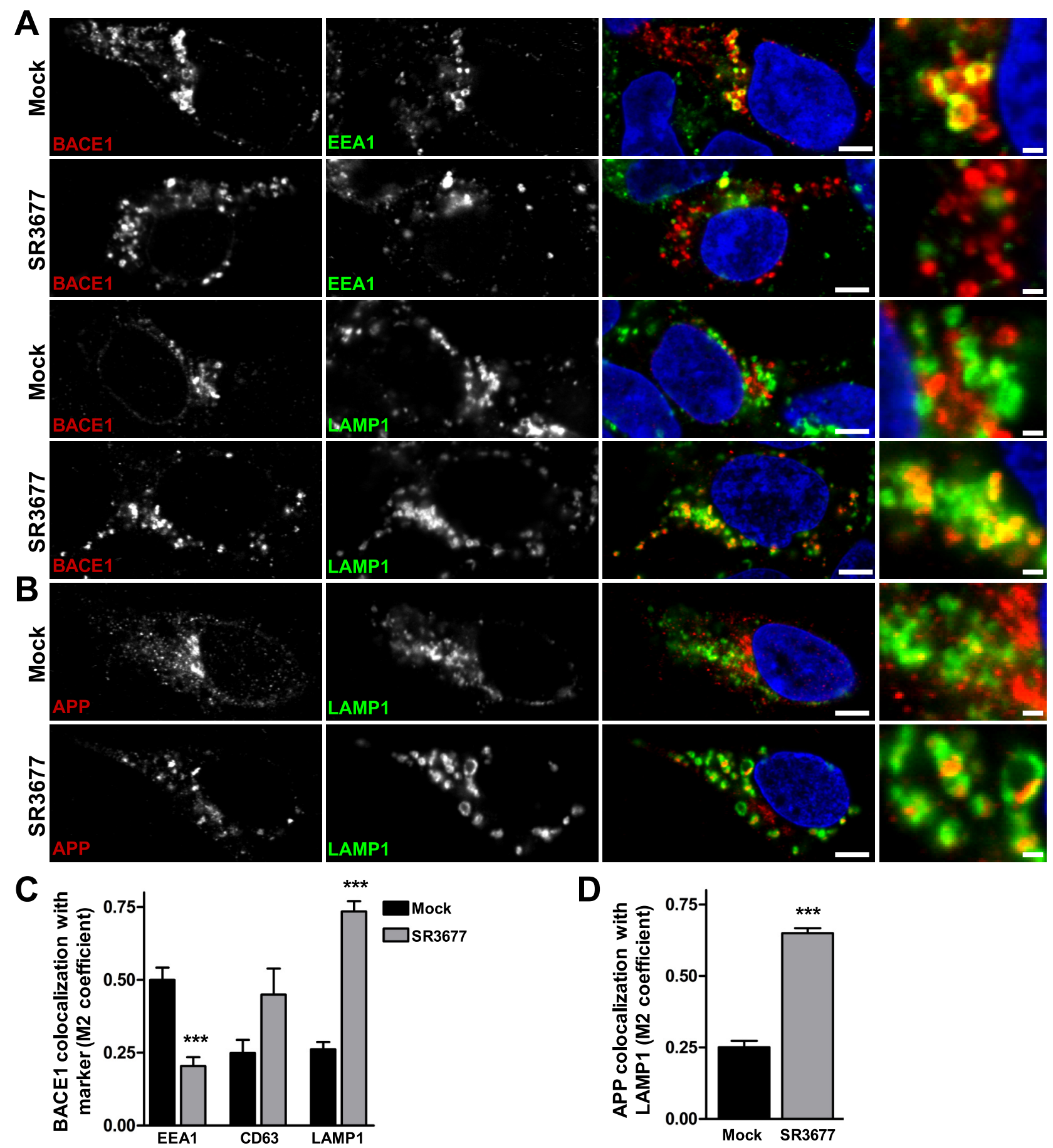

Figure 5. SR3677 promotes BACE1 and APP traffic to lysosomes. HEK293 cells were transfected with plasmid expressing BACE1. BACE1 colocalization with the following organelle markers: EEA1, CD63, and LAMP1 were evaluated after $6 \mathrm{~h}$ of treatment with $50 \mu \mathrm{m}$ SR3677. A, Representative images of BACE1 (red) and organelle markers (green), with colocalization (yellow), are shown in the merged and zoom-in image. $\boldsymbol{B}$, Representative images of endogenous APP (red) and LAMP1 (green), with colocalization (yellow) are shown in the merged and zoom-in image. $\boldsymbol{C}$, Quantitative analyses of BACE1 staining. SR3677 reduced BACE1 overlap with EEA1 (mock, M2 $=0.5 ; \mathrm{SR3677,M2}=0.2044 ;{ }^{* * *} p<0.0001$ ). SR3677 increased BACE1 colocalization with CD63, but the change was not significant compared with mock (mock, M2 $=0.2493 ;$ SR3677, M2 $=0.4499$ ). SR3677 increased BACE1 overlap with LAMP1 (mock, M2 $=0.2614 ; S R 3677, M 2=0.735 ; * * * p<0.0001$ ). $D$, Quantitative analyses of endogenous APP staining. SR3677 increased APP colocalization with LAMP1 (mock, M2 $=0.2510 ;$ SR3677, M2 $=0.6501$; ${ }^{* * *} p<0.0001$ ). Values are shown as the mean \pm 1 SD (error bars). Data shown are representative of three independent experiments. Scale bars: merged image, $5 \mu \mathrm{m} ;$ zoom-in image, $1 \mu \mathrm{m}$.

activity and curb $A \beta$ generation. Our results show that pharmacologic inhibition of ROCK 2 activity diminishes sAPP $\beta$ production as well as $A \beta$ levels, and the following plausible mechanisms are provided: (1) suppression of BACE1 enzymatic action; (2) altering BACE1 endocytic traffic; and (3) modifying phosphorylation of the APP cytoplasmic tail at T654.
Directly inhibiting the enzymatic activity of the amyloidogenic secretases is fraught with caveats, pertaining to effects on unrelated substrates (De Strooper et al., 2010). One approach to circumvent these issues is to modulate secretase activities as opposed to directly inhibiting them. This approach is being explored for $\gamma$-secretase modulators. An alternative strategy is to 
A
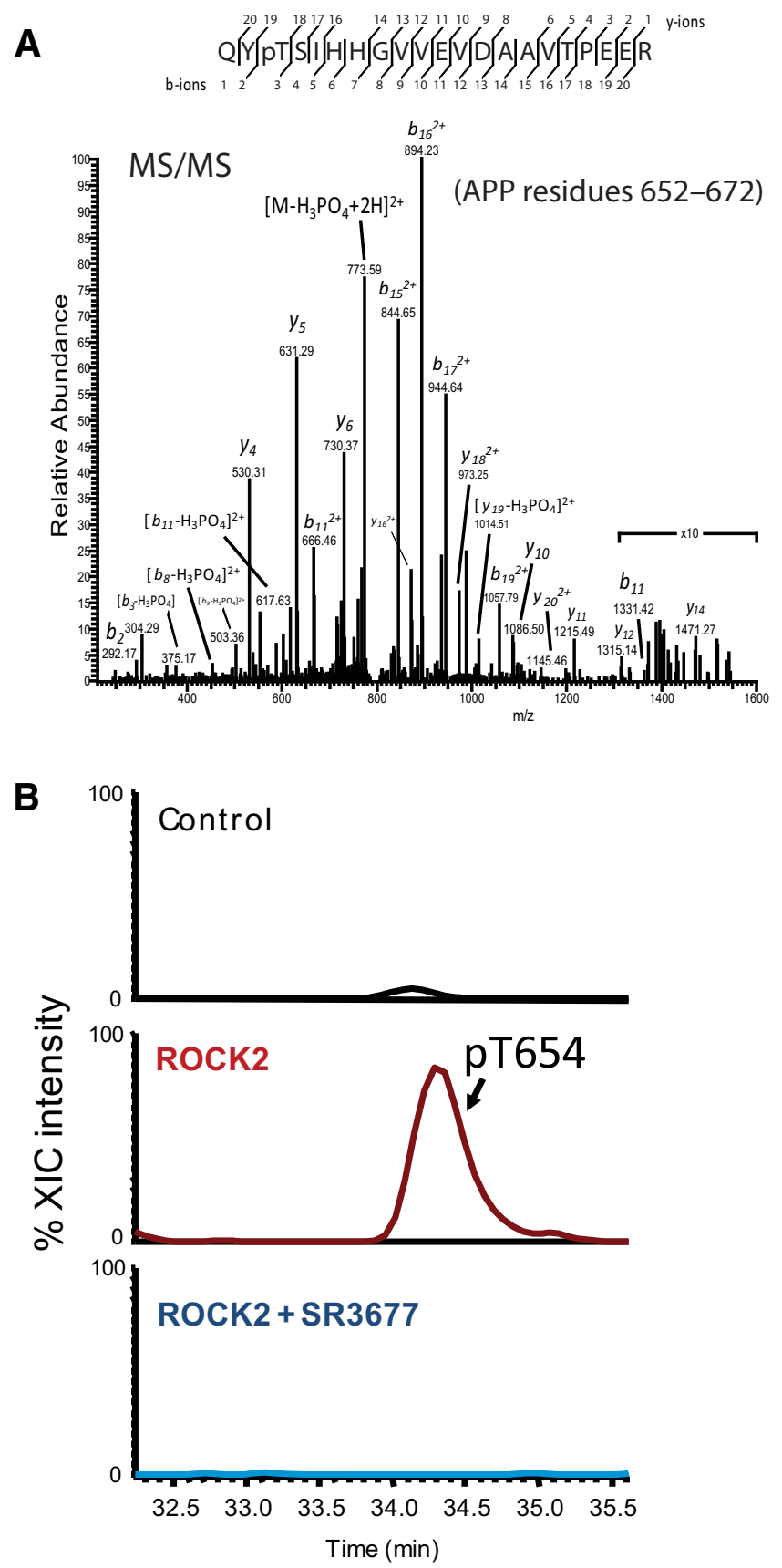
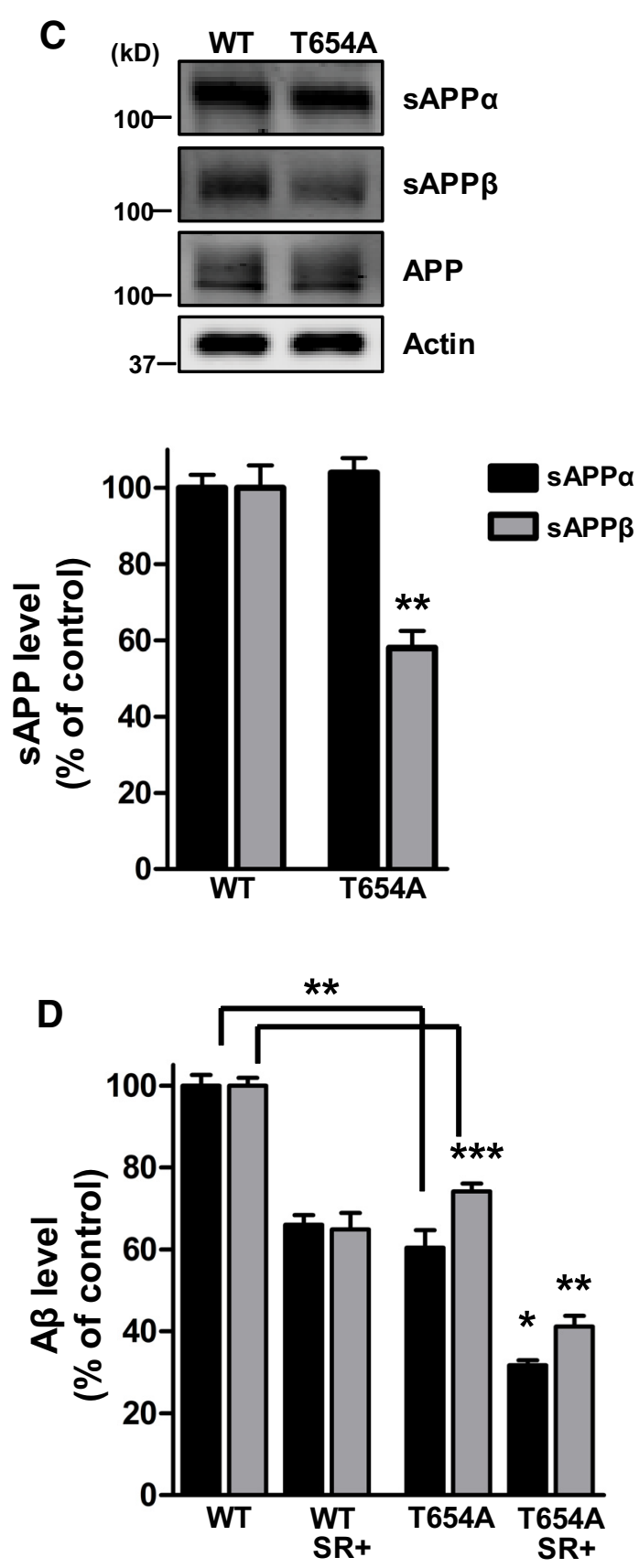

Figure 6. ROCK2 phosphorylates APP at T654, and T654 is critical for A $\beta$ generation in neurons. Furthermore, mutagenesis of APP T654 to alanine (T654A) in combination with SR3677 exposure synergistically reduced $A \beta 40$ and $A \beta 42$ levels, suggesting that inhibition of ROCK2 activity suppresses $A \beta$ production through at least two independent mechanisms. $A$, APP peptides were incubated with recombinant ROCK2 protein \pm SR3677 and were examined by LC-MS/MS. Representative T654 APP phosphopeptide spectrum displaying precursor neutral loss peak. $\boldsymbol{B}$, Representative extracted ion chromatograms (measured as the percentage intensity using a defined precursor mass tolerance) for T654 phosphopeptides. The $x$-axis indicates time when the MS/MS spectrum was obtained. Peptide intensities were normalized to samples containing R0CK2 protein without SR3677. C, Neurons were transduced with lentivirus expressing APP ${ }_{695}$ (WT) or T654A, and sAPP $\alpha$ and sAPP $\beta$ were measured (representative blot shown). Densitometry analysis indicated that sAPP $\beta$ was reduced $42 \%$ from neurons expressing T654A. ${ }^{* *} p=0.0047 . D$, A 340 and $A \beta 42$ levels were reduced 40\% and 26\%, respectively, from neurons expressing T654A (A $\beta 40:$ WT vs T654A, ${ }^{* *} p=0.0014 ; A \beta 42:$ WT vs T654A, ${ }^{* * * *} p=0.0006 ;$ T654A:A $\beta 40$ vs $\left.A \beta 42,{ }^{*} p=0.0425\right)$. Exposure to SR3677 (SR+) reduced $A \beta 40$ and $A \beta 42$ levels $34 \%$ and $35 \%$, respectively, from WT-expressing neurons. SR3677 reduced $A \beta 40$ and $A \beta 42$ levels $68 \%$ and $59 \%$, respectively, from neurons expressing T654A (A $\beta 40:$ T654A vs T654A $+S R,{ }^{*} p=0.0146 ; A \beta 42$ : T654A vs T654A $\left.+S R,{ }^{* *} p=0.0018\right)$. SR, SR3677. A, $\boldsymbol{B}$, Performed in biological triplicate. $C, D, N=3-6$ biological replicates per condition, and all data are expressed as the percentage of the mean \pm SEM with respect to control.

regulate post-translational modification of APP in a way that deters amyloidogenic processing but protects $\alpha$-secretase cleavage of APP. Our findings in neurons indicated that with low-dose $(\leq 10 \mu \mathrm{M})$ treatments of SR3677, APP and $\operatorname{sAPP} \alpha$ levels were not significantly altered, whereas $\mathrm{SAPP} \beta$ production was diminished (Fig. 2C). At higher doses ( $\geq 20 \mu \mathrm{M}), \mathrm{APP}$ and sAPP $\alpha$ levels were marginally lower, but the ratio of $\operatorname{sAPP} \alpha$ to APP remained $\geq 1: 1$ (Fig. 2D). Similarly, in 5XFAD mouse brain, exposure to SR3677 slightly reduced APP levels but depleted sAPP $\beta$ (Fig. 3A). Furthermore, immunofluorescence and confocal microscopy studies revealed that SR3677 promotes APP traffic to LAMP1-positive compartments (Fig. 5D). Under these conditions, it is possible 

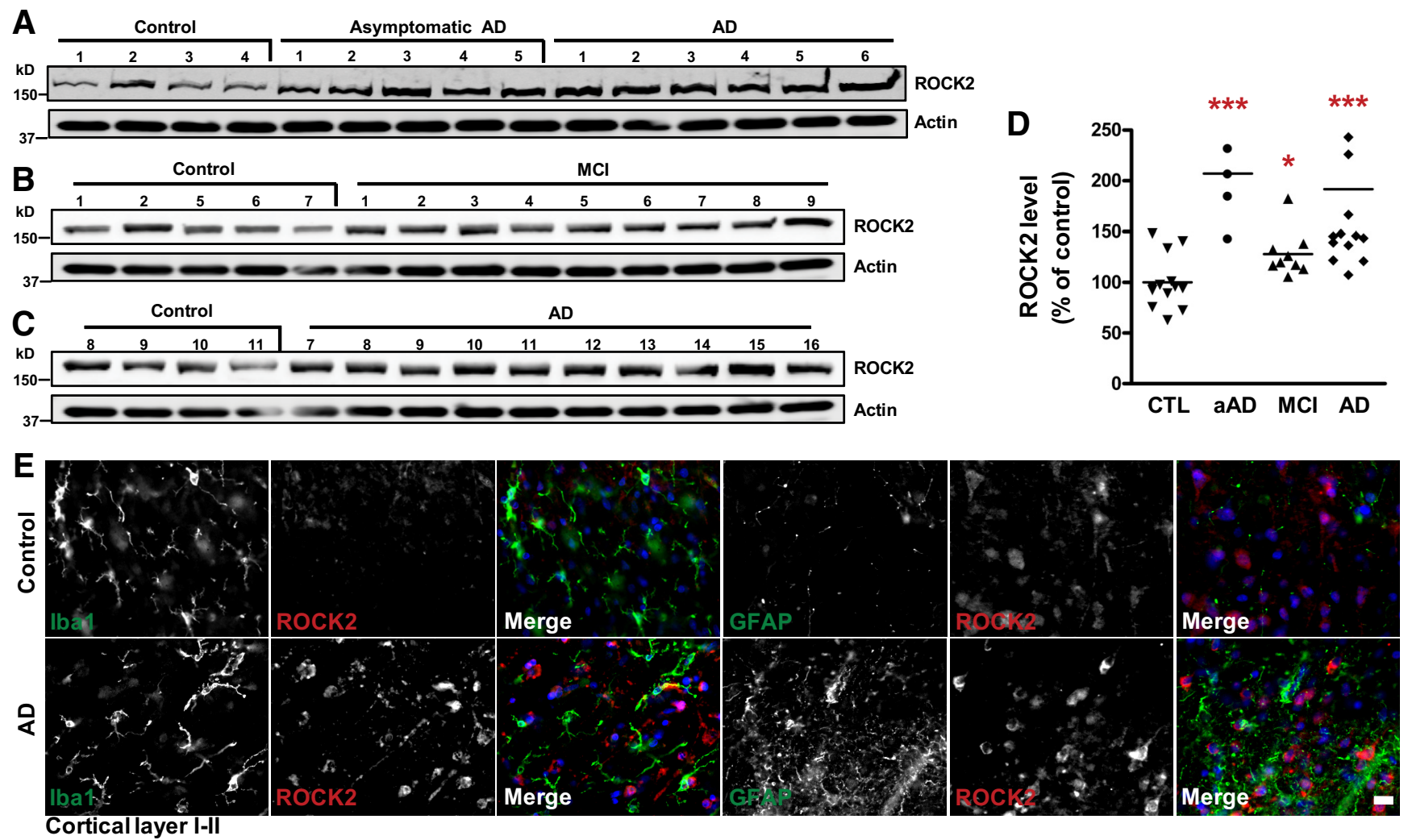

Figure 7. Elevated ROCK2 protein level in human AD brains. A-C, Immunoblots were performed using postmortem frontal cortex homogenates from control (CTL), asymptomatic AD (aAD), MCl, or AD brains. Fifty micrograms were loaded per lane, and ROCK2 levels were normalized to actin. Case numbers correspond to information in Table 1. D, Densitometry analysis indicates that ROCK2 is elevated 107\%, 28\%, and 92\%, respectively, in $\mathrm{AAD}, \mathrm{MCl}$, and AD compared with CTLs. ${ }^{*} p=0.0164,{ }^{* * *} p<0.0009$. Each case is expressed as an individual data point, and lines represent the mean. $E$, Immunohistochemical analyses of ROCK2 in control and AD brains. Representative images of ROCK2 (red) and Iba1 (green) or GFAP (green), with Hoechst (blue) shown in the merged image. Scale bar, $10 \mu \mathrm{m}$

that the observed decrease in APP may be accounted for by (1) enhanced APP recycling and subsequent processing by $\alpha$-secretase, (2) increased APP traffic to degradative pathways, or (3) a combination of both.

We hypothesize that ROCK2 phosphorylates APP at T654 in $v i v o$, and that inhibiting this phosphorylation contributes to the decrease in $\operatorname{sAPP} \beta$ and $\mathrm{A} \beta$ that is observed following treatment with SR3677. Although the functional role of T654 is unknown, T654 is phosphorylated in brain and comprises the YTSI motif, which mediates basolateral sorting of APP (Haass et al., 1995). Nuclear magnetic resonance studies revealed that phosphorylation of T654 induces conformational changes that may stabilize binding of cytosolic factors to the APP C-terminal tail (Ramelot and Nicholson, 2001). Changes in the affinity and/or specificity of APP protein-protein interactions could contribute to the observed effects on $A \beta$ generation. For example, the lipoprotein receptor LR11, or SorLA, complexes with APP through lumenal as well as cytosolic interactions and mediates APP traffic; however, whether APP phosphorylation plays a role in this interaction is unknown (Spoelgen et al., 2006). Notably, LR11 and ROCK2 associate in human brain, and it is possible that binding to LR11 facilitates the effects of ROCK2 on APP processing (Herskowitz et al., 2011). Without a phospho-specific antibody, evaluating whether or not LR11 is critical for ROCK2 phosphorylation of APP T654 in cells is a challenging question. In addition, LR11 interacts with BACE1 (Spoelgen et al., 2006); therefore, the association of ROCK2 with LR11 may be important for the observed effects on BACE1 enzyme action following inhibition of ROCK2 activity.
The opposing outcomes of ROCK1 or ROCK2 knockdown on $\mathrm{A} \beta$ levels suggest that the net result of inhibiting both kinases is a limited effect, which was observed following treatment with RhoI or Y-27632 (Figs. $1 A, 2 A$ ). These findings highlight that the effects of ROCK1 and ROCK2 on $A \beta$ production are likely independent of each other, and we hypothesize that selective inhibition of ROCK1 would increase A $\beta$ generation. Previous work demonstrated that the expression of a constitutively active ROCK1 mutant (CA-ROCK1) reduced sAPP $\alpha$ levels, whereas a dominant-negative ROCK1 mutant (DN-ROCK1) increased sAPP $\alpha$ levels in N2a murine neuroblastoma cells overexpressing APP with Swedish mutations (Pedrini et al., 2005). Additional experiments revealed that the expression of CA-ROCK1 or DNROCK1 had no effect on $\mathrm{A} \beta$ production in human cells (Leuchtenberger et al., 2006). In the present study, we show that RNAi depletion of ROCK1 in human neuroblastoma cells does not significantly alter endogenous full-length APP or sAPP $\alpha$ levels, but substantially increases A $\beta 40$ production (Fig. $1 B--E$ ). Deeper analysis of $\beta$ - and/or $\gamma$-secretase processing of endogenous APP following RNAi depletion of ROCK1 may help elucidate how ROCK1 influences the generation of $A \beta$.

Currently, Fasudil is the only clinically available ROCK inhibitor, but it lacks selectivity to ROCK1 or ROCK2 (Shibuya et al., 2005). Our comparison of Fasudil to SR3677 indicates that an isoform-selective ROCK2 inhibitor may be a more effective approach to reduce amyloidogenic processing of APP in AD (Fig. $2 E$ ). The kinase inhibitor profile for SR3677 included an extensive panel of kinases and other non-kinase-relevant enzymes and receptors (Feng et al., 2008). Of 353 kinases, SR3677 hit only 5 
kinases with inhibition $>50 \%$. Moreover, SR3677 demonstrated an approximately eightfold selectivity of ROCK2 over ROCK1. With an off-target hit rate of 1.4\%, SR3677 is considered one of the best known ATP-competitive kinase inhibitors (Karaman et al., 2008). Clearly, more work is needed before isoform-selective ROCK inhibitors reach the clinic; however, the potential for these compounds to combat $\mathrm{A} \beta$ production for the treatment of $\mathrm{AD}$ raises considerable enthusiasm.

\section{References}

Amano M, Tsumura Y, Taki K, Harada H, Mori K, Nishioka T, Kato K, Suzuki T, Nishioka Y, Iwamatsu A, Kaibuchi K (2010) A proteomic approach for comprehensively screening substrates of protein kinases such as Rhokinase. PLoS One 5:e8704. CrossRef Medline

Bolte S, Cordelières FP (2006) A guided tour into subcellular colocalization analysis in light microscopy. J Microsc 224:213-232. CrossRef Medline

Citron M, Teplow DB, Selkoe DJ (1995) Generation of amyloid beta protein from its precursor is sequence specific. Neuron 14:661-670. CrossRef Medline

Cole SL, Vassar R (2007) The Alzheimer's disease beta-secretase enzyme, BACE1. Mol Neurodegener 2:22. CrossRef Medline

De Strooper B, Vassar R, Golde T (2010) The secretases: enzymes with therapeutic potential in Alzheimer disease. Nat Rev Neurol 6:99-107. CrossRef Medline

Donovan LE, Higginbotham L, Dammer EB, Gearing M, Rees HD, Xia Q, Duong DM, Seyfried NT, Lah JJ, Levey AI (2012) Analysis of a membrane-enriched proteome from postmortem human brain tissue in Alzheimer's disease. Proteomics Clin Appl 6:201-211. CrossRef Medline

Driscoll I, Troncoso J (2011) Asymptomatic Alzheimer's disease: a prodrome or a state of resilience? Curr Alzheimer Res 8:330-335. CrossRef Medline

Feng Y, Yin Y, Weiser A, Griffin E, Cameron MD, Lin L, Ruiz C, Schürer SC, Inoue T, Rao PV, Schröter T, Lograsso P (2008) Discovery of substituted 4-(pyrazol-4-yl)-phenylbenzodioxane-2-carboxamides as potent and highly selective Rho kinase (ROCK-II) inhibitors. J Med Chem 51:66426645. CrossRef Medline

Fukumoto H, Cheung BS, Hyman BT, Irizarry MC (2002) Beta-secretase protein and activity are increased in the neocortex in Alzheimer disease. Arch Neurol 59:1381-1389. CrossRef Medline

Goate A, Chartier-Harlin MC, Mullan M, Brown J, Crawford F, Fidani L, Giuffra L, Haynes A, Irving N, James L, et al. (1991) Segregation of a missense mutation in the amyloid precursor protein gene with familial Alzheimer's disease. Nature 349:704-706. CrossRef

Haass C, Koo EH, Capell A, Teplow DB, Selkoe DJ (1995) Polarized sorting of beta-amyloid precursor protein and its proteolytic products in MDCK cells is regulated by two independent signals. J Cell Biol 128:537-547. CrossRef Medline

Hardy J (1997) The Alzheimer family of diseases: many etiologies, one pathogenesis? Proc Natl Acad Sci U S A 94:2095-2097. CrossRef Medline

Hartmann T, Bieger SC, Brühl B, Tienari PJ, Ida N, Allsop D, Roberts GW, Masters CL, Dotti CG, Unsicker K, Beyreuther K (1997) Distinct sites of intracellular production for Alzheimer's disease A beta40/42 amyloid peptides. Nat Med 3:1016-1020. CrossRef Medline

Herskowitz JH, Seyfried NT, Duong DM, Xia Q, Rees HD, Gearing M, Peng J, Lah JJ, Levey AI (2010) Phosphoproteomic analysis reveals site-specific changes in GFAP and NDRG2 phosphorylation in frontotemporal lobar degeneration. J Proteome Res 9:6368-6379. CrossRef Medline

Herskowitz JH, Seyfried NT, Gearing M, Kahn RA, Peng J, Levey AI, Lah JJ (2011) Rho kinase II phosphorylation of the lipoprotein receptor LR11/ SORLA alters amyloid-beta production. J Biol Chem 286:6117-6127. CrossRef Medline

Herskowitz JH, Offe K, Deshpande A, Kahn RA, Levey AI, Lah JJ (2012) GGA1-mediated endocytic traffic of LR11/SorLA alters APP intracellular distribution and amyloid-beta production. Mol Biol Cell 23:2645-2657. CrossRef Medline

Jonsson T, Atwal JK, Steinberg S, Snaedal J, Jonsson PV, Bjornsson S, Stefansson H, Sulem P, Gudbjartsson D, Maloney J, Hoyte K, Gustafson A, Liu Y, Lu Y, Bhangale T, Graham RR, Huttenlocher J, Bjornsdottir G, Andreassen OA, Jönsson EG, et al. (2012) A mutation in APP protects against Alzheimer's disease and age-related cognitive decline. Nature 488:96-99. CrossRef Medline
Karaman MW, Herrgard S, Treiber DK, Gallant P, Atteridge CE, Campbell BT, Chan KW, Ciceri P, Davis MI, Edeen PT, Faraoni R, Floyd M, Hunt JP, Lockhart DJ, Milanov ZV, Morrison MJ, Pallares G, Patel HK, Pritchard S, Wodicka LM, et al. (2008) A quantitative analysis of kinase inhibitor selectivity. Nat Biotechnol 26:127-132. CrossRef Medline

Koh YH, von Arnim CA, Hyman BT, Tanzi RE, Tesco G (2005) BACE is degraded via the lysosomal pathway. J Biol Chem 280:32499-32504. CrossRef Medline

Koo EH, Squazzo SL (1994) Evidence that production and release of amyloid beta-protein involves the endocytic pathway. J Biol Chem 269: 17386-17389. Medline

Lee DH, Shi J, Jeoung NH, Kim MS, Zabolotny JM, Lee SW, White MF, Wei L, Kim YB (2009) Targeted disruption of ROCK1 causes insulin resistance in vivo. J Biol Chem 284:11776-11780. CrossRef Medline

Lee MS, Kao SC, Lemere CA, Xia W, Tseng HC, Zhou Y, Neve R, Ahlijanian MK, Tsai LH (2003) APP processing is regulated by cytoplasmic phosphorylation. J Cell Biol 163:83-95. CrossRef Medline

Leuchtenberger S, Kummer MP, Kukar T, Czirr E, Teusch N, Sagi SA, Berdeaux R, Pietrzik CU, Ladd TB, Golde TE, Koo EH, Weggen S (2006) Inhibitors of Rho-kinase modulate amyloid-beta (Abeta) secretion but lack selectivity for Abeta42. J Neurochem 96:355-365. CrossRef Medline

Masters CL, Simms G, Weinman NA, Multhaup G, McDonald BL, Beyreuther K (1985) Amyloid plaque core protein in Alzheimer disease and Down syndrome. Proc Natl Acad Sci U S A 82:4245-4249. CrossRef Medline

Mullan M, Crawford F, Axelman K, Houlden H, Lilius L, Winblad B, Lannfelt L (1992) A pathogenic mutation for probable Alzheimer's disease in the APP gene at the N-terminus of beta-amyloid. Nat Genet 1:345-347. CrossRef Medline

Murrell J, Farlow M, Ghetti B, Benson MD (1991) A mutation in the amyloid precursor protein associated with hereditary Alzheimer's disease. Science 254:97-99. CrossRef Medline

Nakagawa O, Fujisawa K, Ishizaki T, Saito Y, Nakao K, Narumiya S (1996) ROCK-I and ROCK-II, two isoforms of Rho-associated coiled-coil forming protein serine/threonine kinase in mice. FEBS Lett 392:189-193. CrossRef Medline

Oakley H, Cole SL, Logan S, Maus E, Shao P, Craft J, Guillozet-Bongaarts A, Ohno M, Disterhoft J, Van Eldik L, Berry R, Vassar R (2006) Intraneuronal $\beta$-amyloid aggregates, neurodegeneration, and neuron loss in transgenic mice with five familial Alzheimer's disease mutations: potential factors in amyloid plaque formation. J Neurosci 26:10129-10140. CrossRef Medline

Oishi M, Nairn AC, Czernik AJ, Lim GS, Isohara T, Gandy SE, Greengard P, Suzuki T (1997) The cytoplasmic domain of Alzheimer's amyloid precursor protein is phosphorylated at Thr654, Ser655, and Thr668 in adult rat brain and cultured cells. Mol Med 3:111-123. Medline

Pedrini S, Carter TL, Prendergast G, Petanceska S, Ehrlich ME, Gandy S (2005) Modulation of statin-activated shedding of Alzheimer APP ectodomain by ROCK. PLoS Med 2:e18. CrossRef Medline

Ramelot TA, Nicholson LK (2001) Phosphorylation-induced structural changes in the amyloid precursor protein cytoplasmic tail detected by NMR. J Mol Biol 307:871-884. CrossRef Medline

Sannerud R, Declerck I, Peric A, Raemaekers T, Menendez G, Zhou L, Veerle B, Coen K, Munck S, De Strooper B, Schiavo G, Annaert W (2011) ADP ribosylation factor 6 (ARF6) controls amyloid precursor protein (APP) processing by mediating the endosomal sorting of BACE1. Proc Natl Acad Sci U S A 108:E559-E568. CrossRef Medline

Selkoe DJ, Podlisny MB, Joachim CL, Vickers EA, Lee G, Fritz LC, Oltersdorf T (1988) Beta-amyloid precursor protein of Alzheimer disease occurs as 110- to 135-kilodalton membrane-associated proteins in neural and nonneural tissues. Proc Natl Acad Sci U S A 85:7341-7345. CrossRef Medline

Shibuya M, Hirai S, Seto M, Satoh S, Ohtomo E (2005) Effects of fasudil in acute ischemic stroke: results of a prospective placebo-controlled doubleblind trial. J Neurol Sci 238:31-39. CrossRef Medline

Shock NW GR, Andres R, Arenberg D, Costa Jr, PT, Lakatta EG, Tobin JD (1984) Normal human aging: the Baltimore Longitudinal Study of Aging. Bethesda, MD: NIH 84-2450.

Sisodia SS (1992) Beta-amyloid precursor protein cleavage by a membranebound protease. Proc Natl Acad Sci U S A 89:6075-6079. CrossRef Medline

Sperling RA, Aisen PS, Beckett LA, Bennett DA, Craft S, Fagan AM, Iwatsubo T, Jack CR Jr, Kaye J, Montine TJ, Park DC, Reiman EM, Rowe CC, 
Siemers E, Stern Y, Yaffe K, Carrillo MC, Thies B, Morrison-Bogorad M, Wagster MV, et al. (2011) Toward defining the preclinical stages of Alzheimer's disease: recommendations from the National Institute on Aging-Alzheimer's Association workgroups on diagnostic guidelines for Alzheimer's disease. Alzheimers Dement 7:280-292. CrossRef Medline

Spoelgen R, von Arnim CA, Thomas AV, Peltan ID, Koker M, Deng A, Irizarry MC, Andersen OM, Willnow TE, Hyman BT (2006) Interaction of the cytosolic domains of sorLA/LR11 with the amyloid precursor protein (APP) and $\beta$-secretase $\beta$-site APP-cleaving enzyme. J Neurosci 26 : 418-428. CrossRef Medline

Stachel SJ (2009) Progress toward the development of a viable BACE-1 inhibitor. Drug Dev Res 70:101-110. CrossRef

Totsukawa G, Yamakita Y, Yamashiro S, Hartshorne DJ, Sasaki Y, Matsumura F (2000) Distinct roles of ROCK (Rho-kinase) and MLCK in spatial regulation of MLC phosphorylation for assembly of stress fibers and focal adhesions in 3T3 fibroblasts. J Cell Biol 150:797-806. CrossRef Medline

Uehata M, Ishizaki T, Satoh H, Ono T, Kawahara T, Morishita T, Tamakawa H, Yamagami K, Inui J, Maekawa M, Narumiya S (1997) Calcium sensitization of smooth muscle mediated by a Rho-associated protein kinase in hypertension. Nature 389:990-994. CrossRef Medline von Arnim CA, Tangredi MM, Peltan ID, Lee BM, Irizarry MC, Kinoshita A, Hyman BT (2004) Demonstration of BACE (beta-secretase) phosphorylation and its interaction with GGA1 in cells by fluorescencelifetime imaging microscopy. J Cell Sci 117:5437-5445. CrossRef Medline

Xu G, Stevens SM Jr, Moore BD, McClung S, Borchelt DR (2013) Cytosolic proteins lose solubility as amyloid deposits in a transgenic mouse model of Alzheimer-type amyloidosis. Hum Mol Genet 22:2765-2774. CrossRef Medline

Yang LB, Lindholm K, Yan R, Citron M, Xia W, Yang XL, Beach T, Sue L, Wong P, Price D, Li R, Shen Y (2003) Elevated beta-secretase expression and enzymatic activity detected in sporadic Alzheimer disease. Nat Med 9:3-4. CrossRef Medline

Zhang Y, Li X, Qi J, Wang J, Liu X, Zhang H, Lin SC, Meng A (2009) Rock2 controls TGFbeta signaling and inhibits mesoderm induction in zebrafish embryos. J Cell Sci 122:2197-2207. CrossRef Medline

Zhou Y, Su Y, Li B, Liu F, Ryder JW, Wu X, Gonzalez-DeWhitt PA, Gelfanova V, Hale JE, May PC, Paul SM, Ni B (2003) Nonsteroidal antiinflammatory drugs can lower amyloidogenic Abeta 42 by inhibiting Rho. Science 302:1215-1217. CrossRef Medline 